\title{
Perspectivas de transformación educativa en la Escuela de Aviación del Ejército de Colombia. El programa de Ingeniería Aeronáutica como caso de estudio ${ }^{1}$
}

\author{
https://doi.org/10.21830.9789585350663.08
}

\author{
Andrés Eduardo Fernández Osorio ${ }^{2}$ \\ Escuela Militar de Cadetes "General José María Córdova" \\ Jonatan Eduardo Figueroa Peña \\ Yuly Vanessa Espinel Silva ${ }^{4}$ \\ Escuela de Aviación del Ejército
}

\begin{abstract}
Resumen. Los procesos de autoevaluación han demostrado tradicionalmente su aporte a la calidad de los programas educativos y a la mejora continua de la preparación de los estudiantes. No obstante, aunque su aplicación en las instituciones universitarias colombianas es ampliamente difundida y la literatura generada es abundante, la producción académica sobre autoevaluación en el sistema de educación de las Fuerzas Militares en Colombia es bastante escasa y en el caso del Ejército Nacional, casi inexistente. Este capítulo de libro busca contribuir a la solución de ese vacío de conocimiento al explorar las perspectivas de transformación educativa en el Centro de Educación Militar - Escuela de Aviación del Ejército de Colombia, tomando como caso de estudio el programa de
\end{abstract}

1 Este capítulo presenta los resultados del proyecto de investigación "Caracterización del perfil pedagógico de los profesores e instructores de las Escuelas de Formación y Capacitación del Ejército Nacional", del grupo de investigación en Aviación Militar de la Escuela de Aviación del Ejército (EsAve), categorizado en C por Minciencias y con código de registro COL0077618. Los puntos de vista pertenecen a los autores y no reflejan necesariamente los de las instituciones participantes.

2 Teniente Coronel del Ejército Nacional de Colombia. PhD en Derecho y Ciencia Política de la Universidad de Barcelona, Espańa. Magíster en Estudios de Defensa del King’s College London, Reino Unido. Magíster en Economía, Estado y Sociedad: Política y Seguridad de la Universidad Colegio de Londres, Reino Unido. Magíster en Relaciones Internacionales de la Escuela Superior de Economía, Moscú, Federación de Rusia. Magíster en Seguridad y Defensa Nacionales de la Escuela Superior de Guerra "General Rafael Reyes Prieto". OrCID: https://orcid.org/0000-0003-0643-0258 - Contacto: andres. fernandez@esmic.edu.co

3 Mayor del Ejército Nacional de Colombia. Especialista en Administración de Unidades Militares y Especialista en Administración de Recursos para la Defensa Nacional de la Escuela de Armas Combinadas del Ejército. Administrador de empresas de la Universidad Militar Nueva Granada. Profesional en Ciencias Militares de la Escuela Militar de Cadetes "General José María Córdova". OrCid: https://orcid.org/0000-0003-3226-2729 - Contacto: jonatanfigueroapena@cedoc.edu.co

4 Teniente del Ejército Nacional de Colombia. Profesional en Ciencias Militares y administradora logística de la Escuela Militar de Cadetes "General José María Córdova". Orcid: https://orcid. org/0000-0001-5827-5929 - Contacto: yulyespinelsilva@cedoc.edu.co 
Ingeniería Aeronáutica. Para tal fin, se analizan con una metodología cuantitativa los resultados del primer momento de autoevaluación realizada en esa institución y se transversalizan a la luz de tres hipótesis sobre la percepción de la calidad del pregrado de Ingeniería Aeronáutica. Los resultados más significativos indican que: (1) la percepción de los tres grupos observados (directivos, profesores y estudiantes) se mantiene concentrada entre los rangos medio y alto de satisfacción general; (2) las fortalezas y oportunidades de mejora son identificadas en forma unificada por todos los participantes, y (3) aspectos como la organización académica, la relación con el sector externo y los medios educativos son las condiciones que más resaltan positivamente en la institución.

Palabras clave: autoevaluación; aviación; Colombia; educación militar; Ejército Nacional; ingeniería aeronáutica.

\section{Introducción}

Durante el siglo XIX Colombia fue uno de los países más atrasados del mundo en temas educativos (Ramírez \& Salazar, 2010), lo cual afectó negativamente el desarrollo económico, social y político de la República. Por esta razón, a partir de la creación del Ministerio de Instrucción Pública a través de la Ley 7 de 1886, que posteriormente en 1928 se convertiría en el Ministerio de Educación Nacional (MEN), diferentes gobiernos implementaron lineamientos con el fin de mejorar la calidad de la educación.

Dentro de esta evolución, una de las herramientas con mayor relevancia en la continua búsqueda de la excelencia ha sido el proceso de autoevaluación, ya que permite reflexionar sobre los procesos y fortalecer la cultura de mejoramiento de la calidad (Panadero-Calderón \& Alonso-Tapia, 2013). Así mismo, facilita los espacios de autocrítica dentro de un modelo constructivo para la reformulación de las prácticas educativas y administrativas que pueden afectar la calidad deseada de los programas académicos (González et al., 2004). Por esta razón, en la guía para el mejoramiento institucional de la autoevaluación, el MEN (2008) presenta algunos lineamientos que permiten fortalecer las competencias profesionales y la calidad de las instituciones universitarias para un perfeccionamiento continuo en la educación, con el liderazgo de sus directivos (Henao, 2018).

En este contexto, y dado que los programas de educación superior de las Fuerzas Militares se rigen por los lineamientos del Men, el Ejército Nacional de Colombia, a través del Comando de Educación y Doctrina (Cedoc), ha 
buscado establecer planes y políticas para la mejora continua de la formación de sus hombres y mujeres en los diferentes programas académicos ofertados (Comando de Educación y Doctrina, 2019). De igual forma, una de sus unidades subordinadas, el Centro de Educación Militar (CEMiL), a través de sus once escuelas (figura 1), contribuye a la capacitación diferencial de uniformados según sus especialidades en la Fuerza, así como de la comunidad interesada en los programas académicos que ofrece esta institución (CEMIL 2019).

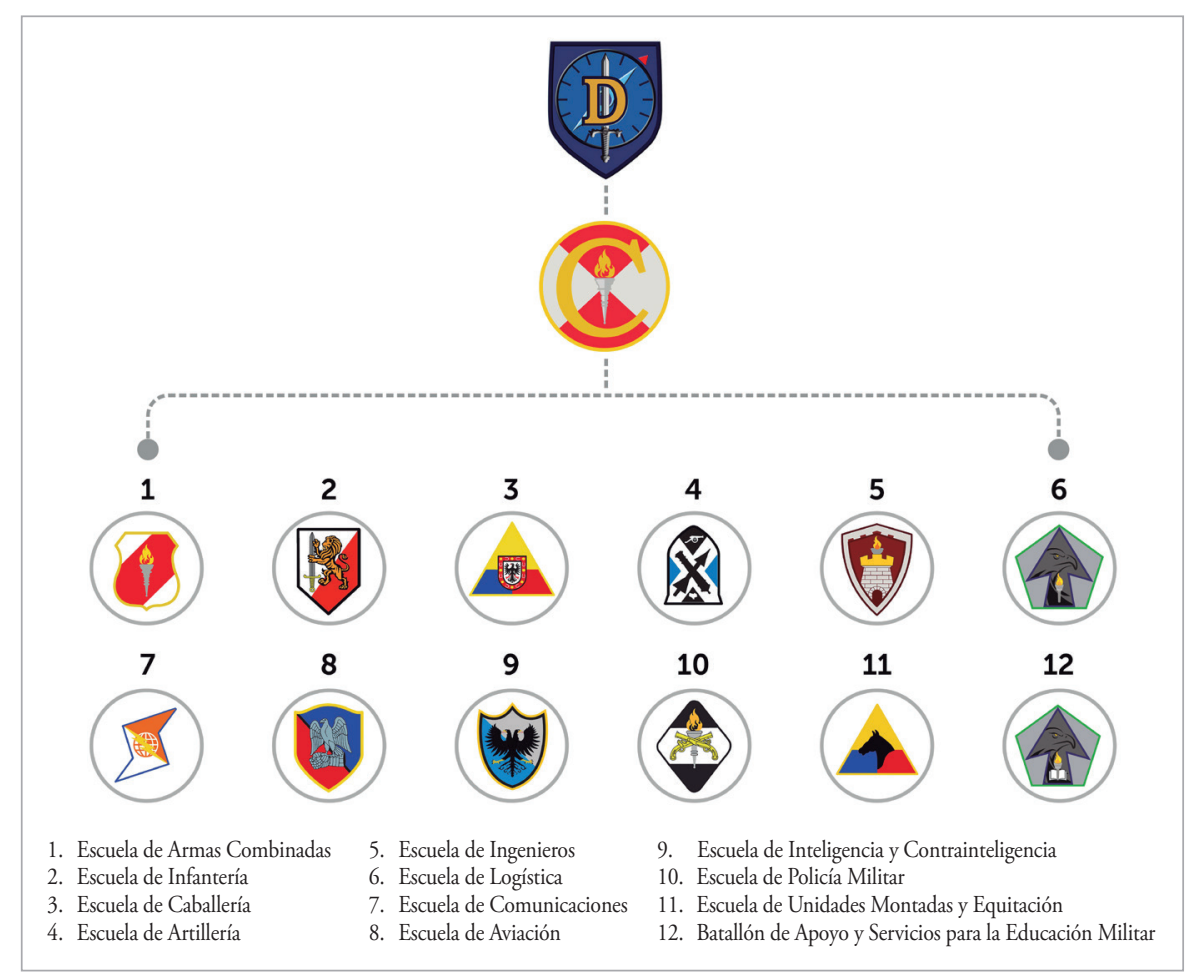

Figura 1. Organización institucional del CemiL.

Fuente: Cemil (2020b).

Aunque la literatura sobre los procesos de autoevaluación en instituciones universitarias aplicables a Colombia es abundante (Flórez-Nisperuza \& Hoyos-Merlano, 2020; García et al., 2013; Guillén et al., 2018; Losio \& Macri, 2015; Valdés et al., 2015) y aborda diversos aspectos sobre su diseño (Arnaiz \& Azorín, 2017; Londońo \& Ramírez, 2012; Murcia-Peña et al., 2009), implementación (Jaramillo \& Villegas, 1998; López, 2004; Pabón, 
1996) y entendimiento (Espinoza \& Poblete, 1994; Flórez-Nisperuza \& Hoyos-Merlano, 2020; Palacios, 2013), la producción académica sobre autoevaluación aplicada a las instituciones de educación de las Fuerzas Militares en Colombia es bastante escasa y en el caso del Ejército Nacional, casi inexistente.

En efecto, a excepción de los aportes de Camelo Villamil (2010), Castellanos Sandoval (2020), Pinto Guzmán (2017), Ramírez Rubiano y Ramírez Bravo (2015), y Vidales et al. (2011), realizados en su mayoría como trabajos de pregrado y maestría, el estudio y la comprensión de los procesos de autoevaluación educativa de las Fuerzas Militares han estado ausentes del debate y de las publicaciones académicas. Por tal motivo, este capítulo de libro busca contribuir a la solución de ese vacío de conocimiento al explorar las perspectivas de transformación educativa en la Escuela de Aviación del Ejército de Colombia (EsAve) tomando como caso de estudio el programa de Ingeniería Aeronáutica. En consecuencia, el problema de investigación de este documento es identificar cuáles son las perspectivas de transformación educativa (fortalezas y oportunidades de mejora) del programa para optimizar los procesos existentes, desarrollar la autocrítica de directivos, estudiantes y docentes, y contribuir a la transformación de la educación militar complementaria.

$\mathrm{Al}$ respecto, la literatura sobre autoevaluación ofrece aportes a la solución del problema de investigación, toda vez que permite caracterizar este tipo de desarrollos como procesos de estudio de una institución o de una de sus partes (facultad, departamento, unidad de servicio o programa), organizados y conducidos por sus propios integrantes, a la luz de los fines institucionales y algún conjunto aceptado de estándares de desempeño (Arnaiz \& Azorín, 2017; Fraile, 2020; Murillo, 2008). De igual forma, aportan elementos descriptivos, pero principalmente analíticos y reflexivos, que suponen un compromiso con el cambio (Espinoza \& Poblete, 1994).

$\mathrm{Al}$ seguir este enfoque, los resultados obtenidos en esta investigación beneficiarán al programa de Ingeniería Aeronáutica de la EsAve, y en forma específica a los docentes y estudiantes, a través del fortalecimiento de la calidad de los contenidos curriculares, con lo cual se logra a la postre que se establezca una cultura de mejora continua mediante la aplicación periódica de procesos para alcanzar la excelencia académica. Sumado a esto, se podrá comprender de una mejor forma las necesidades diferenciales de la población que integra 
el programa de Ingeniería Aeronáutica, cuyo enfoque es el mantenimiento de aeronaves, de tal manera que permita la adecuación de los contenidos académicos que formarán profesionales más competentes que realicen aportes significativos a la seguridad operacional de la Aviación del Ejército de Colombia y a la industria aeronáutica nacional.

En la primera sección se presenta el contexto que enmarca los procesos de autoevaluación en educación superior en Colombia, y en especial en las Fuerzas Militares y el Ejército Nacional de Colombia. De igual forma, se justifica la selección del programa de Ingeniería Aeronáutica para este estudio y sus particularidades. La segunda sección explica la metodología empleada para el estudio, la construcción y organización de los instrumentos de recolección de datos y los enfoques para su interpretación. La tercera sección analiza los resultados de cada una de las nueve condiciones investigadas, así como sus tendencias, las cuales son transversalizadas en la cuarta sección a la luz de las fortalezas y las oportunidades de mejora identificadas. Finalmente, en la quinta sección se realizan algunas conclusiones, se exploran las limitaciones del estudio y se ofrecen puntos de inicio para investigaciones futuras.

\section{Contexto del estudio y marco teórico}

A raíz de la evolución del conflicto armado en Colombia y de los nuevos retos y desafíos para los que las Fuerzas Militares deben estar preparadas en cumplimiento de su misión constitucional, ha surgido, especialmente en el Ejército Nacional, la necesidad de implementar programas de educación superior militar y complementaria para satisfacer las necesidades de preparación profesional. Si bien algunos de estos programas educativos están íntimamente ligados al escenario castrense, como los pregrados en Ciencias Militares o Educación Física Militar, de la Escuela Militar de Cadetes “General José María Córdova”, o las especializaciones en Ciencias Militares para el Planeamiento o en Administración de Recursos Militares para la Defensa Nacional, del Cemil-Escuela de Armas Combinadas del Ejército, algunos otros comparten elementos, contenidos y aplicación con programas ofrecidos por instituciones universitarias públicas y privadas.

Uno de estos ejes de interés nacional compartido entre las Fuerzas Militares y la academia es el sector aeronáutico, toda vez que, además de desempeñar un 
papel fundamental en el desarrollo y la proyección de Colombia en la región de Latinoamérica y el Caribe, es fuente de permanente investigación, desarrollo e innovación. La evolución de la tecnología, la necesidad de expansión de los mercados nacionales, regionales y globales, así como la obligación de interconexión con el mundo han impulsado a la aviación en Colombia, así como a un significativo número de instituciones, incluyendo al Ejército Nacional, a aportar iniciativas, capacidades y experiencia para lograr avances cada vez más significativos (Amaya \& Rodríguez, 2020; Hoyos, 2010; Sánchez, 2018).

Respondiendo a esa necesidad de país, se creó el programa de Ingeniería Aeronáutica en cinco instituciones del país: la Fundación Universitaria Los Libertadores, la Universidad San Buenaventura, la Universidad Pontificia Bolivariana, la Universidad de Investigación y Desarrollo y el Cemil. En efecto, el Ejército Nacional no ha sido ajeno a esta evolución en las necesidades del sector aeronáutico, toda vez que dentro de sus tropas cuenta con la Aviación del Ejército, la cual brinda movilidad y maniobra a las unidades de la Fuerza. Por tal motivo, en 2016 implementó el programa de Ingeniería Aeronáutica del Cemil, administrado por la EsAve, para contribuir a las necesidades propias de la dinámica operacional de la Fuerza, enfocándose en el mantenimiento aeronáutico diferencial para aeronaves militares y su segura operación en ambientes complejos (Díaz, 2018; Guacaneme \& Segura, 2013).

De esta forma, el sector aeronáutico colombiano y de la región recibe permanentemente contribuciones académicas del sistema de educación del Ejército, a través del programa de Ingeniería Aeronáutica del Cemil - EsAve, así como de otras instituciones universitarias públicas y privadas con programas similares, de manera que se ha creado un contexto unificado de proyección social por trabajo mancomunado entre el Estado, la academia y la ciudadanía (Pontificia Universidad Javeriana, 2020; Salazar, 2013).

\section{Características del programa de Ingeniería Aeronáutica en el Ejército}

En el año 2003, mediante Disposición 000008 del 28 de abril de 2003 y Resolución 0533 del 27 de junio del mismo año, fue creada y activada la Escuela de Aviación del Ejército Nacional de Colombia, y a su vez aprobadas sus tablas de organización y equipo. Inició sus labores en el Fuerte Militar de 
Tolemaida y en el año 2004 fue trasladada a las actuales instalaciones en la nueva zona de aviación Campo Aéreo "General José Joaquín Matallana Bermúdez", en la ciudad de Bogotá, D. C. El 21 de marzo de 2014, la Esave inauguró sus nuevas instalaciones, dotadas con los medios necesarios para cumplir con su misión de capacitar al personal de oficiales, suboficiales y soldados de la Aviación del Ejército con el fin de sostener las operaciones militares y cumplir así con su misión institucional (EsAve, 2019).

Con el objetivo de profesionalizar a los oficiales, suboficiales y civiles en el área de mantenimiento aeronáutico, el 28 de enero de 2016 el Ministerio de Educación Nacional otorgó por un término de siete años el registro calificado N. 105208 del programa de Ingeniería Aeronáutica al Cemil-Esave con la modalidad presencial en la ciudad de Bogotá, D. C. Este pregrado se encuentra registrado en el Sistema Nacional de Información de la Educación Superior (SNIEs) con las características descritas en la tabla 1.

Tabla 1. Información del programa

\begin{tabular}{ll}
\hline Nombre del programa & Ingeniería Aeronáutica \\
\hline Código SNIES del programa & 105208 \\
Reconocimiento del Ministerio & Registro calificado \\
Resolución de aprobación N. ${ }^{\circ}$ & 1296 \\
Nivel académico & Pregrado \\
Nivel de formación & Universitaria \\
Modalidad & Presencial \\
Municipio de oferta del programa & Bogotá, D. C. \\
Admisión & Semestral \\
Campo amplio CiNE & Ingeniería, industria y construcción \\
Campo específico CINE & Ingeniería y profesiones afines \\
Campo detallado CinE & Vehículos, barcos y aeronaves de motor \\
Área de conocimiento & Ingeniería, arquitectura, urbanismo y afines \\
Núcleo básico del conocimiento & Ingeniería mecánica y afines \\
\hline
\end{tabular}
Fuente: SNIES (2021). 
La misión del programa de Ingeniería Aeronáutica de la Escuela de Aviación del Ejército es "proyectar a sus egresados como líderes integrales con conocimientos específicos que suplan las necesidades en el campo aeronáutico; ingenieros competitivos que dirijan y ejecuten actividades de creación, investigación, diseño, evaluación, mantenimiento, administración y generación de la capacidad para solucionar los problemas de la industria aeronáutica" (CEMIL, 2020a). En cuanto a su visión, el programa busca "consolidar su sistema de investigación, aprovechando las oportunidades de carácter local, nacional y la fortaleza de sus investigadores, para ejercer liderazgo en la solución de problemas en la División de Aviación Asalto Aéreo del Ejército de Colombia y en el sistema nacional de Ciencia, Tecnología e Innovación del país" (Cemil, 2020a).

Finalmente, el objetivo general de este pregrado es "formar profesionales que den solución a problemas de la industria aeronáutica de una manera creativa e innovadora a fin de garantizar la seguridad aérea de aeronaves tripuladas y no tripuladas" (Esave, 2017). Dada la importancia del pregrado de Ingeniería Aeronáutica para el Ejército Nacional, y la necesidad de garantizar su calidad académica, el CemiL, por intermedio de la EsAVE, dispuso que se realizara el primer momento de la autoevaluación del programa, el cual arrojó unos resultados que deben ser explorados en perspectiva y que son objeto de análisis del presente capítulo.

\section{Fundamentos y dinámicas de la autoevaluación académica}

Los procesos de mejora continua de toda institución educativa, y en especial los de las instituciones universitarias, buscan identificar en forma oportuna las opciones de mejora de sus programas educativos, establecer planes de mejoramiento y acercarse cada vez más al nivel de calidad deseado. No obstante, estos procesos son complejos y requieren la identificación y medición de una vasta cantidad de factores, algunos no contribuyentes en forma directa, que permitan perfeccionar la calidad del conocimiento transmitido a los estudiantes.

Es así como dentro de la mejora continua surge la autoevaluación de las instituciones como una propuesta innovadora, pero que requiere el compromiso y la confianza entre la institución, los profesores y los alumnos para iden- 
tificar en forma correcta las falencias que se deben tratar. En efecto, cuando no se comprende la autoevaluación en todas sus dimensiones y perspectivas, se percibe como un simple proceso fundamentado en "recoger y analizar información de forma sistemática (limitándose a las fases finales del curso), que nos permite formular juicios relativos al alumno, al programa, al propio profesorado (ya que solo se dirige hacia los alumnos como sujetos a examinar)" (Fraile, 2020, p. 7).

Por este motivo, y tal como lo sugiere López Pastor (2004), la evaluación se configura como una encrucijada didáctica que aliena el resto de aspectos didácticos del proceso educativo. Desafortunadamente, los contenidos educativos, objetivos, metodología y recursos pasan a un segundo plano, pues la institución se enfoca únicamente en los resultados cuantitativos de las evaluaciones y, por lo tanto, descuida la actualización de los programas, la satisfacción del profesorado y los estudiantes, así como el cumplimiento de la responsabilidad social de la academia.

Ahora bien, la autoevaluación es un instrumento que no solo permite la detección de malas prácticas, sino que también contribuye a identificar aspectos e iniciativas positivas dignas de ser exaltadas y replicadas en el resto de los programas y en la institución. Así mismo, facilita establecer el nivel de inclusión del cuerpo profesoral y estudiantil dentro de la comunidad académica y su relación con la administración. En efecto, y tal como lo establecen Arnaiz y Azorín (2017), "la atención a la diversidad del alumnado es considerada como un importante indicador de la calidad de la enseñanza que refleja la capacidad de un centro para responder a las características y a los intereses de sus discentes" (p. 228). En la misma línea, con respecto a la utilización positiva de la autoevaluación se puede decir que constituye un sistema de perfeccionamiento continuo, por cuanto "no hay calidad sin inclusión, pues en una sociedad democrática la educación o es inclusiva o no se puede llamar educación” (Arnaiz \& Azorín, 2017, p. 229).

En la literatura se pueden identificar tres enfoques diferentes sobre la autoevaluación y las metodologías para realizarla; no obstante, en todos se resalta la necesidad de continuar la exploración de aspectos pedagógicos frente a su utilidad pedagógica y a los mecanismos para fomentarla entre los profesores y los alumnos. El primer enfoque corresponde a la autoevaluación sin criterios 
de parametrización, el segundo es la autoevaluación a través de rúbricas y el tercero es la autoevaluación con la utilización de guiones (Panadero-Calderón \& Alonso-Tapia, 2013, p. 172).

La autoevaluación sin criterios de parametrización corresponde al proceso donde el estudiante evalúa o califica su trabajo al finalizarlo sin que se le haya hecho entrega de los criterios de evaluación (Panadero-Calderón \& AlonsoTapia, 2013). La autoevaluación a través de rúbricas hace referencia al ambiente donde los estudiantes comparan su trabajo con los estándares que aparecen en la rúbrica y buscan su calificación. Finalmente, la autoevaluación con el uso de guiones hace referencia a "las ayudas que se proporcionan durante el proceso de una actividad, normalmente en forma de pregunta, para sugerir al alumno que la responda para sî" (Panadero-Calderón \& Alonso-Tapia, 2013, p. 184). Son precisamente estos fundamentos teóricos y enfoques sobre la autoevaluación los que tiene en cuenta el presente estudio, contemplando la postulación de iniciativas que permitan alcanzar logros tangibles en la calidad educativa y en la relación profesional entre sus miembros.

En esta búsqueda de la excelencia, el sistema de educación en Colombia también ha evolucionado a través de los años, lo cual es de gran importancia para lograr la prosperidad económica y social del país, para lo cual ha empleado las mejores tendencias de acceso, calidad y equidad (Organización para la Cooperación y el Desarrollo Económicos [OCDE], 2016). Por esta razón se requiere generar un sistema educativo sólido, reconocido por sus buenas prácticas, adecuada rendición de cuentas y un mejoramiento constante obtenido de ellas, de tal manera que se garantice que los diferentes actores trabajen de forma conjunta en busca de los mismos objetivos. Estos sistemas educativos sólidos se construyen con procesos de autoevaluación rigurosos, que contribuyen a la alta calidad y la excelencia en sus programas académicos, condición esencial de las instituciones educativas del mundo desarrollado.

Por lo anterior, este estudio se fundamenta en la normatividad que soporta la calidad, mejora continua y autoevaluación del modelo educativo colombiano que debe atender cualquier institución académica. Es por esto que se tuvo en cuenta la Ley 30 de 1992, que organiza el servicio público de la educación superior; el Acuerdo 02 del 2020, que actualiza el modelo de acreditación en alta calidad; la Ley 115 de 1994, que corresponde a la Ley 
General de Educación; el Decreto 1330 de 2019, que reglamenta aspectos sobre la Educación Superior en Colombia; la Resolución 021795 del 2020, que establece parámetros de autoevaluación, verificación y evaluación de las condiciones de calidad, y la Resolución 015224 del 2020, que establece parámetros de autoevaluación, verificación y evaluación de las condiciones de calidad institucional.

Como aporte a la búsqueda de la mejora continua, a través de la Ley 30 de 1992 el Estado colombiano creó el Sistema Nacional de Acreditación (SNA) y el Consejo Nacional de Acreditación (CNA) para garantizar la autonomía universitaria y altos niveles de calidad en el sistema educativo. Estos organismos realizan inspección y vigilancia detallada a los procesos que atiende la educación superior del país, haciendo cumplir los requisitos exigidos con el objetivo de brindar una transparencia a la sociedad en general. De igual forma, el artículo 2.5.3.2.1.2 del Decreto 1075 de 2015 establece el Sistema de Aseguramiento de la Calidad de la Educación Superior, donde se define como "el conjunto de instituciones e instancias, las cuales se articulan por medio de políticas y procesos diseñados con el propósito de asegurar la calidad de las instituciones y de sus programas académicos" (Men, 2015, p. 4).

A su vez, el Acuerdo 2 del 2020 establece los lineamientos para realizar el trámite de acreditación en alta calidad, tanto para los programas como para las instituciones, que consiste en las siguientes etapas: Apreciación de condiciones iniciales, Autoevaluación, Evaluación externa por pares académicos, Evaluación integral y Expedición del acto administrativo que concede la acreditación o formulación de recomendaciones a la institución (Men, 2020a). Si bien el gobierno nacional emite a través del MEN los lineamientos para llevar a cabo el proceso de autoevaluación en las instituciones académicas en el país, las instituciones castrenses a su vez también emiten lineamientos de autoevaluación dentro de cada una de estas y rigiéndose por el ordenamiento jurídico referente a la educación (Ley 115 de 1994, Ley 1064 de 2016, Decreto 1075 de 2015 y Decreto 1330 de 2019) y sus modificaciones.

Dicho esto, según la Ley 30 de 1992, el Men garantiza la autonomía universitaria y vela por la calidad del servicio educativo a través del ejercicio de la suprema inspección y vigilancia de la educación superior. Con este propósito se creó el Consejo Nacional de Educación Superior (CESU), con funciones 
de coordinación, planificación, recomendación y asesoría. El CESU, además, a través del Instituto Colombiano para el Fomento de la Educación Superior (ICFEs), funge como el órgano encargado de estimular y perfeccionar los procedimientos de autoevaluación institucional, tarea que deben desarrollar en forma permanente las instituciones de educación superior. Asimismo, existe el denominado Sistema de Información de la Educación Superior (SNIES), el cual está encargado de divulgar información para orientar a la comunidad sobre la calidad, la cantidad y las características de las instituciones y programas del sistema.

Así entonces, las instituciones de educación superior deberán demostrar el cumplimiento de condiciones de calidad de los programas y condiciones de calidad de carácter institucional (Art. 2, Ley 1188 de 2008). Es relevante mencionar que las condiciones de calidad a que se hace referencia no son más que características institucionales necesarias que facilitan y promueven el desarrollo de las labores formativas, académicas, docentes, científicas, culturales y de extensión de las instituciones (Decreto 1075 de 2015). Como se ha dicho, el Men es el encargado de vigilar el cumplimiento de las condiciones de calidad, tanto institucionales como del programa, de ahí que exija el cumplimiento de estas mediante el otorgamiento de un registro calificado que avala a las instituciones universitarias para ofertar y desarrollar programas de educación superior por un lapso de siete ańos. En caso de que las instituciones no cuenten con esta acreditación luego de este tiempo, deben solicitar la renovación del registro. En consecuencia, el registro calificado es el instrumento del Sistema de Aseguramiento de la Calidad de la Educación Superior mediante el cual el Estado verifica el cumplimiento de las condiciones de calidad por parte de las instituciones de educación superior (Ley 1188 de 2008) (CNA, 2019).

Habiendo ya descrito los órganos e instrumentos existentes para apoyar el ejercicio de mejora continua dentro del Men, es preciso resaltar el proceso que realiza cada institución de educación superior para lograr alinearse con los requerimientos exigidos por el Ministerio: la autoevaluación. Esta se define como un ejercicio institucional que parte de la autonomía universitaria y permea todas las instancias, tanto administrativas como académicas, con lo cual se crea una cultura institucional orientada al reconocimiento de buenas prácticas y a su mejoramiento continuo (Men, 2020b). 
En efecto, los procesos de autoevaluación buscan develar el estado real de los programas frente a las condiciones de calidad, previa revisión y análisis de los resultados obtenidos de la aplicación de una serie de instrumentos. En la mayoría de los casos se trata de encuestas que buscan determinar la percepción que tiene cada uno de los estudiantes, los profesores y el personal administrativo de la comunidad académica, lo cual arroja como resultado un plan de mejoramiento que orienta los diferentes procesos y aporta a la adopción de políticas de mejora continua que garanticen altos estándares de calidad.

Por lo expuesto anteriormente y con el fin dar cumplimiento a todos los lineamientos del Men y ajustarse a los estándares de calidad diferenciales que demanda la educación militar, el Ministerio de Defensa Nacional, del cual dependen las instituciones militares y de policía, emitió sus propios lineamientos de calidad mediante la "Política Educativa de la Fuerza Pública (Pefur) 2019-2032 Hacia una Educación Inteligente, Estratégica y de Calidad”, cuyo origen se basa en los documentos existentes para el año 2019.

Los esfuerzos y resultados del pasado fueron continuados y profundizados a través del Proyecto Educativo de las Fuerzas Armadas (PefA), Sistema Educativo de las Fuerzas Armadas (SEFA) y Plan Estratégico del Sistema Educativo de las Fuerzas Armadas (PESE), documentos creados en el ańo 2007 que terminaron por constituirse en el instrumento rector en materia con vigencia hasta el año 2019. Estos documentos establecieron trece criterios para la educación del personal uniformado, denominados "Políticas Orientadoras", los cuales sirvieron como punto de partida para la "Política Educativa de la Fuerza Pública" (Pefup) 2019-2032: Hacia una Educación Inteligente, Estratégica y de Calidad', la cual es la respuesta natural a los cambios que se presentan en el contexto estratégico nacional e internacional. (Ministerio de Defensa Nacional, 2019)

Esta política está compuesta por cuatro capítulos que evolucionan en forma transversal y propenden a la calidad educativa. El primer capítulo trata sobre los fundamentos básicos de la educación en la Fuerza Pública, el segundo describe la visión de la educación al año 2032, el tercero establece los parámetros para el seguimiento y la evaluación de esta política, y el cuarto, y último, compila un glosario de términos sobre el sistema educativo de la Fuerza Pública. Es importante aclarar que el tema de autoevaluación se encuentra enmarcado dentro del tercer capítulo de forma general, incluyendo los respon- 
sables de las iniciativas mencionadas, el tiempo en el que se deben cumplir y los correspondientes criterios de éxito e indicadores (Ministerio de Defensa Nacional, 2019).

Tomando en cuenta que el Pefup emite unos lineamientos generales, cada una de las Fuerzas estableció a su vez sus propios lineamientos ajustándose a la normativa de los Ministerios de Educación y de Defensa. Es así como el Ejército Nacional de Colombia, por intermedio de su Jefatura de Estado Mayor de Planeación y Políticas (Jempr) y el Departamento de Educación Militar (CEDE-7), emite los parámetros del Sistema Integrado de Aseguramiento de la Calidad Educativa del Ejército Nacional (SiaceE).

Lo anterior es coherente con la oferta académica del Ejército Nacional, la cual es administrada a través del Comando de Educación y Doctrina (CEDOC) y el Centro de Educación Militar (CEMIL) y sus escuelas de capacitación, puesto que los programas de pregrado y posgrado del Ejército Nacional tienen registro calificado otorgado por el MEN mediante acto administrativo y se encuentran en las bases de datos del Sistema Nacional de Información de la Educación Superior (SNIes) (Jefatura de Estado Mayor de Planeación y Políticas, 2019).

Estos lineamientos establecen la búsqueda por mantener un proceso de mejoramiento continuo dentro de la institución, con el fin de alcanzar altos estándares de calidad y de esta manera dar cumplimiento a la misión constitucional. En efecto, esta última no se podría llevar a cabo si la oferta académica propia de la institución no cumple con los requerimientos del gobierno nacional, por esto se realiza constantemente la evaluación de esta oferta y se busca la mejora de los procesos, de tal manera que se ajusten a los estándares requeridos.

De esta forma, el SiACEE establece la metodología de la autoevaluación para el Ejército Nacional en cuatro fases diferenciadas (figura 2). Con base en esta metodología, todas las unidades inmersas en el proceso educativo deben realizar sus actividades académicas para dar cumplimiento a los lineamientos e integrar el proceso de mejora continua que permite el cumplimiento de la misión de esta fuerza militar. 


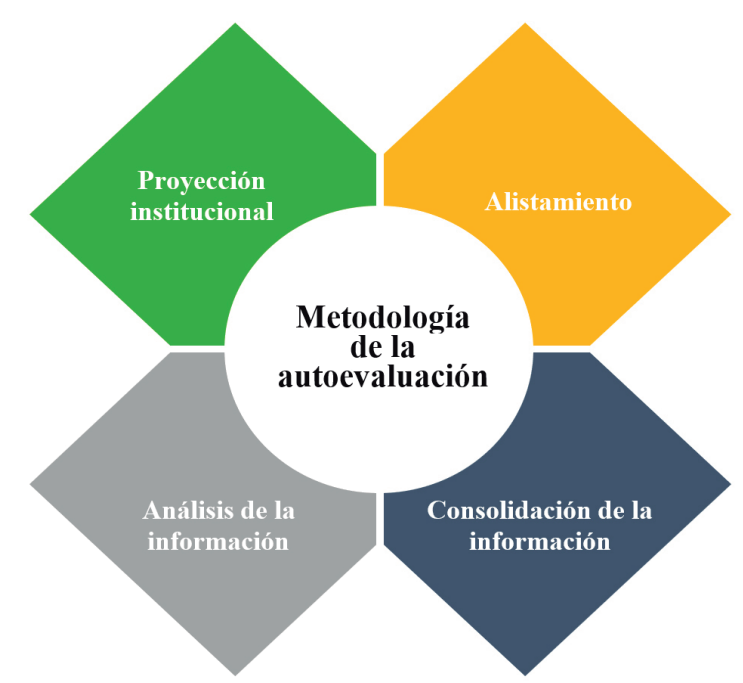

Figura 2. Metodología de la autoevaluación para el Ejército Nacional. Fuente: elaboración propia con base en los datos del SIACEE.

Aunque los lineamientos descritos anteriormente rigen a cada una de las unidades subordinadas del CEDOC, deben ser analizados y evaluados por estas unidades con el fin de ajustarlos a la especificidad de cada uno de los programas que integran la oferta académica. Es por esto que el CemiL, que actualmente es la unidad rectora de las escuelas de capacitación del Ejército Nacional, establece los procedimientos para realizar la autoevaluación de cada uno de los programas de la institución universitaria CEMIL.

$\mathrm{Al}$ respecto, el documento rector del proceso académico en el Cemil es el Acuerdo N. 006 - Políticas Institucionales, donde se describe la autoevaluación como una cultura que no se puede llevar a cabo como un proceso aislado en el cual las personas trabajan de forma descentralizada, sino que debe ser un proceso cíclico integrado. Este se debe adelantar en forma permanente y debe permitir analizar los procesos que se llevan a cabo para el desarrollo de cada uno de los programas y facilitar la realización de las acciones requeridas para alcanzar altos estándares de calidad.

En este punto es importante establecer la definición de cultura de autoevaluación que utiliza este trabajo, la cual se adscribe a los lineamientos que establece el Men a través del artículo 2.5.3.2.3.1.4 del Decreto 1330 de 2019 en los siguientes términos: 
El conjunto de mecanismos que las instituciones tienen para el seguimiento sistemático del cumplimiento de sus objetivos misionales, el análisis de las condiciones que afectan su desarrollo, y las medidas para el mejoramiento continuo. Esta cultura busca garantizar que la oferta y desarrollo de programas académicos se realice en condiciones de calidad y que las instituciones rindan cuentas ante la comunidad, la sociedad y el Estado sobre el servicio educativo que presta. La institución deberá demostrar la existencia, divulgación e implementación de políticas institucionales que promuevan la autoevaluación, la autorregulación, y el mejoramiento de acuerdo con su naturaleza jurídica, tipología, identidad y misión institucional, para generar una corresponsabilidad de toda la comunidad académica en el mejoramiento continuo. (MEN, 2019)

En efecto, un modelo de autoevaluación se debe entender como un proceso de análisis, evaluación y verificación interna que se realiza de forma permanente a la institución y sus programas académicos. En este se ejecuta un ejercicio participativo con el fin de identificar y reflexionar sobre las fortalezas y los aspectos por mejorar dentro de la institución, buscando realizar una práctica periódica de autorregulación que permita identificar el estado actual en el que se encuentran los programas académicos impartidos. Mediante este diagnóstico, las instituciones identifican de forma precisa los problemas y los retos más apremiantes, al tiempo que determinan los objetivos de alta prioridad, base sobre la cual se pueden formular planes estratégicos que impacten de forma concluyente en la calidad de los programas académicos (figura 3).

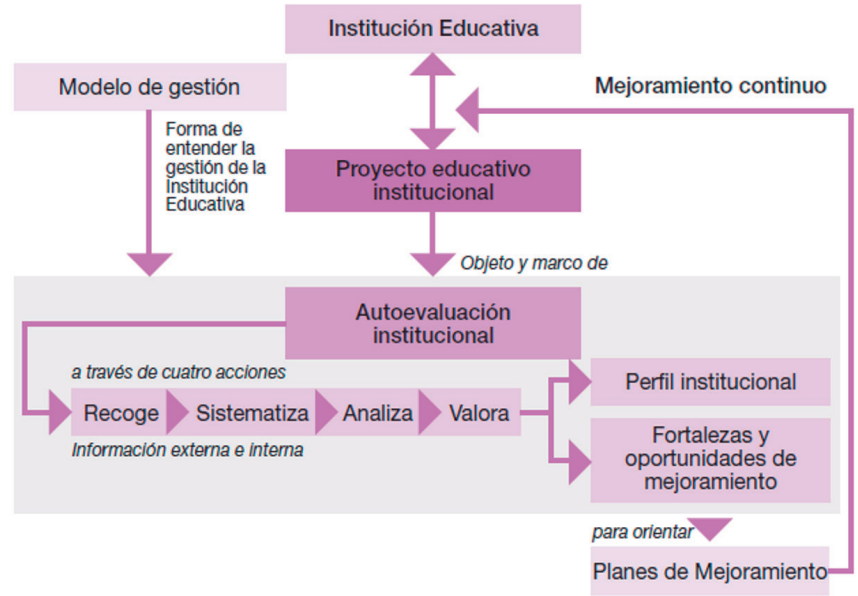

Figura 3. Mapa del proceso de autoevaluación institucional. Fuente: MEN (2013). 
Asimismo, el Men establece los lineamientos para realizar el proceso de autoevaluación institucional, el cual constituye una gestión directiva que compete de forma directa al rector de la institución, quien lo orienta de forma coherente para obtener unos resultados favorables. A su vez, el rector cuenta con el apoyo de su equipo directivo, quienes tienen roles y tareas definidas, y convoca la participación del personal que integra la institución educativa en busca del mejoramiento continuo como compromiso institucional. La siguiente ruta que establece esta guía (figura 4) está conformada por seis pasos, los cuales orientan y facilitan la tarea de la autoevaluación institucional (MEN, 2013).

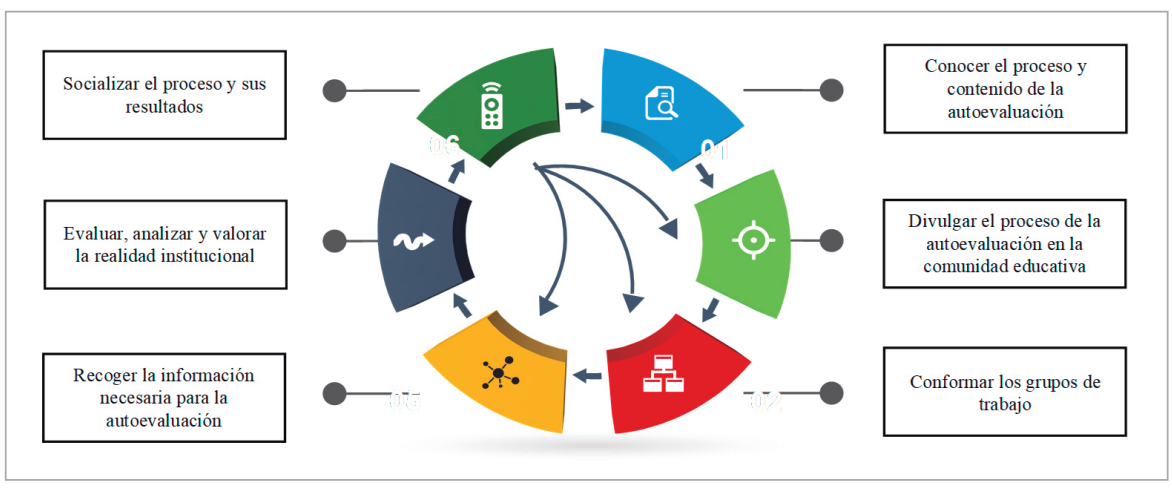

Figura 4. Ruta de autoevaluación institucional.

Fuente: elaboración propia con base en los datos del MEN (2013).

Por lo anterior, se puede afirmar que el objetivo de la autoevaluación es mejorar la calidad de la educación al determinar las fortalezas y las debilidades que se encuentran como resultado de este proceso. Con este propósito, dirige todo el esfuerzo hacia la cooperación activa de la comunidad educativa y tiene presente los principios de veracidad, participación y corresponsabilidad. Así, la autoevaluación realiza un importante aporte al progreso institucional y es la base para la formulación y ejecución del plan de mejoramiento. Este último requiere definir los objetivos, las actividades, los tiempos y los responsables para cada tarea, con el fin de lograr el propósito acordado en cada área de gestión. Es importante realizar un seguimiento periódico a este plan de mejoramiento, de tal manera que sea posible verificar el cumplimiento de los objetivos y las metas trazadas, así como evidenciar si es necesario realizar ajustes oportunos. 


\section{El proceso de autoevaluación académica en la Escuela de Aviación del Ejército}

Ningún programa de educación superior está exento de oportunidades de mejora. Como lo han demostrado diversos autores, las instituciones educativas, en razón a su naturaleza cambiante, se enfrentan a constantes desafíos en la actualización de sus contenidos curriculares, de manera que es necesario identificarlos y buscar su solución (Chemers et al., 2001; Holmes, 1971; Putwain et al., 2016; Trippi \& Stewart, 1989; Van Kraayenoord \& Paris, 1997). Por tal motivo, la Esave inició en 2019 un proceso de autoevaluación con el fin de determinar los diferentes aspectos que afectan a los directivos, los profesores y los estudiantes y que impactan en la calidad del programa de pregrado en Ingeniería Aeronáutica (Motivar, 2015).

Una falencia que se evidenció es que hasta 2019 la EsAve no había realizado un proceso de autoevaluación, lo cual dificultaba la identificación de las fortalezas o posibilidades de mejora del pregrado en Ingeniería Aeronáutica durante los cuatro años que llevaba en curso. Por tal motivo, dando cumplimiento no solo a los requerimientos del Men y del Sistema Educativo de las Fuerzas Armadas, sino también a lo que establece la resolución del 30 de abril del año 2018 del Cemil, se inició el primer momento de autoevaluación de este programa de pregrado, con el fin de comprobar el grado de cumplimiento de sus procesos académico-administrativos, en relación con la normativa nacional e institucional.

Con la motivación de lograr el mejoramiento continuo, la EsAve propuso un modelo para medir las condiciones de calidad del programa de pregrado en Ingeniería Aeronáutica, de tal forma que los resultados permitieran proponer planes de acción con el fin de garantizar la continuidad de los procesos de mejora y asegurar la planeación estratégica del programa. Este modelo se desarrolló en cinco fases (figura 5).

Dado que la Esave no es la única que oferta programas de educación superior en el Ejército Nacional y que las demás escuelas también realizan procesos de autoevaluación, el modelo utilizado se fortaleció con los utilizados por otras escuelas, en especial por la Escuela de Inteligencia y Contrainteligencia (EsICI) y la Escuela de Ingenieros Militares (EsING). Por ejemplo, la EsICI (2020) define la autoevaluación como un proceso permanente de reflexión y acción 


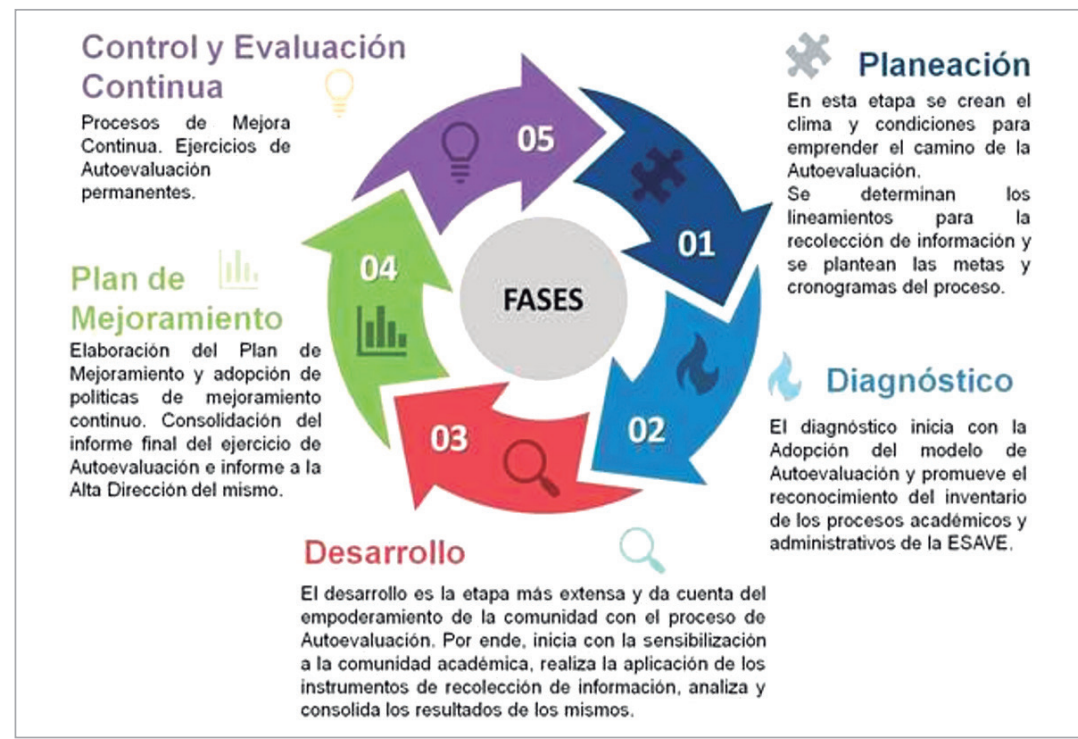

Figura 5. Proceso de autoevaluación en la ESAVE.

Fuente: EsAVE (2020).

para la mejora continua del servicio educativo, cuya finalidad es la calidad deseada y la satisfacción de la comunidad universitaria y de la sociedad en general. Específicamente, la Esici lleva a cabo este proceso mediante la aplicación de cinco fases (figura 6).

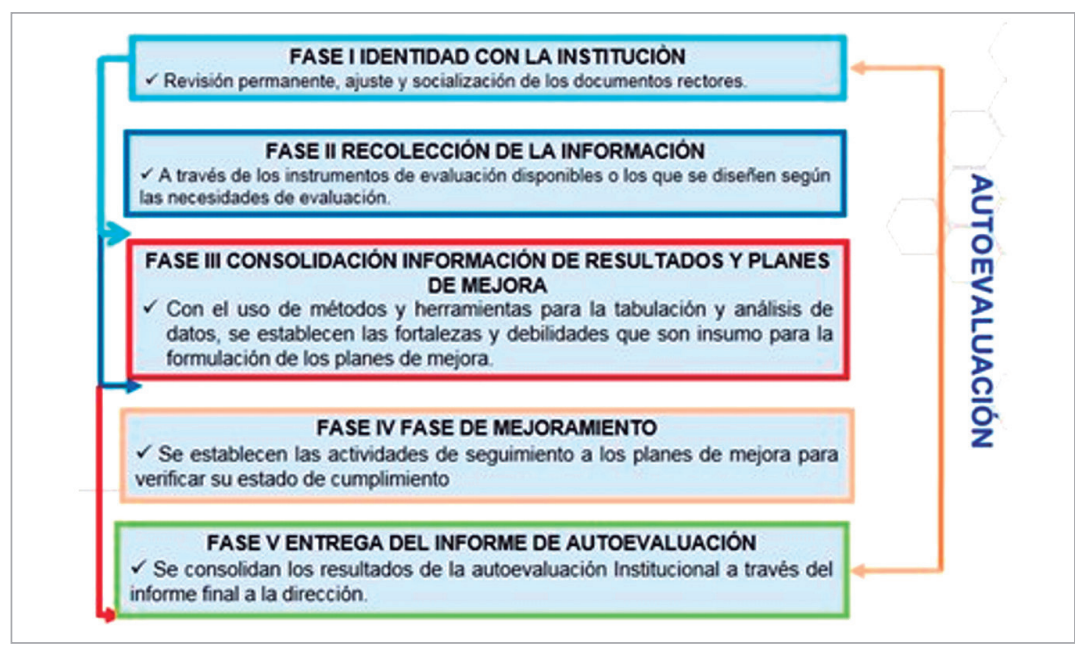

Figura 6. Proceso de autoevaluación en la Esicr.

Fuente: EsICI (2020). 
La Esıci realiza procedimientos básicos de recolección de la información, diseño de instrumentos, análisis y consolidación, recopilación documental, elaboración y entrega del informe al director de la escuela, y, por último, elaboración y seguimiento de los planes de mejoramiento. Es relevante mencionar que esta escuela realiza dicho proceso al finalizar un programa para entender la perspectiva que tienen sus estudiantes.

La evaluación institucional se realiza al finalizar el curso, programa o especialización, con el fin de evaluar las áreas que competen a bienestar universitario, medios educativos y de apoyo, proceso formativo y en general todos los aspectos positivos o por mejorar que tiene el programa. El instrumento es cualitativo-cuantitativo, con el fin de revisar la percepción del estudiante. (EsICI, 2020)

Otra de las unidades que tienen como esencia la capacitación del personal que integra el Ejército Nacional es la Escuela de Ingenieros Militares (EsING), una de las más robustas en temas académicos por la cantidad de programas que ofrece. La EsING adopta la autoevaluación como hilo conductor hacia la excelencia, partiendo del compromiso de cada uno de sus miembros, con lo cual obedece a la calidad de los procesos para la obtención de los mejores resultados (Escuela de Ingenieros Militares [Esıng], 2020).

De esta manera, la EsING desarrolla un proceso de evaluación de desempeño de 360 grados, compuesta por tres tipos de evaluación: el primero es la heteroevaluación, que desarrollan los estudiantes; el segundo es la coevaluación, que lleva a cabo el director del programa, y el tercero y último es la autoevaluación, que está a cargo del docente (figura 7).

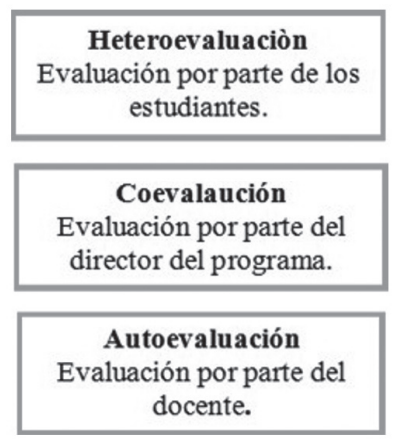

Figura 7. Proceso de autoevaluación en la Esing.

Fuente: EsING (2020). 
Teniendo estas referencias de las instituciones de educación militar, la EsAvE realizó un primer momento del proceso de autoevaluación para identificar las fortalezas y las oportunidades de mejora. Una vez realizada esta etapa, es imperativo analizar los datos recopilados, determinar las buenas prácticas y las prioridades de acción que permitan la mejora continua del sistema de educación de la Fuerza. Asimismo, es preciso identificar las perspectivas de transformación en la educación en la EsAve para avanzar en la calidad de otros programas ofertados, la satisfacción de la comunidad académica y el cumplimiento de la misión institucional.

\section{Metodología}

Este estudio tuvo un carácter hipotético-deductivo con un protocolo cuantitativo, basado en el análisis de percepciones de la muestra de estudio, para determinar la posición de tres grupos definidos de la Esave (directivos, profesores y estudiantes) frente a algunas hipótesis sobre las características del programa de Ingeniería Aeronáutica.

El carácter novedoso de esta investigación generó un gran interés en la comunidad académica, el cual se reflejó en la participación voluntaria de 211 personas, cantidad requerida para que el estudio tuviera un nivel de confianza del $95 \%$ y un margen de error del $5 \%$ (tabla 2). No obstante, al ser la primera ocasión en la que se desarrolló este muestreo, la información recopilada debe interpretarse como la línea de base de un estudio longitudinal que permita explorar la evaluación de las percepciones a lo largo del tiempo.

Tabla 2. Ficha técnica del cuestionario

\begin{tabular}{lccc}
\hline \multicolumn{1}{c}{ Diseño muestral } & Directivos & Profesores & Estudiantes \\
\hline Tamaño del universo & 60 & 21 & 130 \\
Muestra & 53 & 20 & 98 \\
Nivel de confianza & $95 \%$ & $95 \%$ & $95 \%$ \\
Margen de error & $5 \%$ & $5 \%$ & $5 \%$ \\
\hline
\end{tabular}

Fuente: elaboración propia. 
Para recopilar las percepciones de la muestra estudiada se empleó un cuestionario anónimo de respuesta en físico, tipo lápiz y papel, que se administró durante la última semana del mes de septiembre de 2019 en las instalaciones de la Esave, antes del impacto de la Covid-19 en el escenario nacional. Este instrumento fue aprobado por el segundo Comité Local de Ciencia y Tecnología de la EsAVE de 2019 y la Dirección de la institución autorizó el empleo de la información. Antes de aplicar el cuestionario se hicieron dos rondas de pilotaje y validación del instrumento con participantes similares en edad, nivel académico y estrato socioeconómico al grupo estudiado para garantizar el correcto entendimiento de las preguntas y la facilidad de respuesta. Todos los participantes fueron voluntarios y sus identidades protegidas por el carácter anónimo del cuestionario, además, como parte de la lectura y aceptación del consentimiento informado, se les notificó el objetivo del estudio, los investigadores principales, sus derechos como participantes y la posibilidad de que la Esave utilizara la información recopilada en publicaciones académicas.

El cuestionario, construido con base en los lineamientos de autoevaluación del Cemil, buscó ser corto y flexible para obtener respuestas sinceras sin direccionar su contenido, pero tampoco sin desviar la atención a aspectos no relevantes para la institución. No obstante, es necesario señalar que el proceso de autoevaluación de este programa establece al menos dos retos adicionales en razón a las particularidades institucionales y a la conformación de la población directiva, profesoral y estudiantil.

En primer lugar, aunque el programa es dirigido por una institución universitaria militar y su enfoque se centra en las necesidades de las aeronaves del Ejército Nacional, los componentes de interrelación con el sector externo y de evolución tecnológica son mucho más cercanos al sector privado que a las Fuerzas Militares, en razón a que los demás programas son ofertados por universidades civiles y que no existe otro programa similar en la Fuerza Pública colombiana.

En segundo lugar, los grupos estudiados tienen una conformación bastante delimitada que puede llegar a interferir con la obtención e interpretación de los resultados. En efecto, el grupo de directivos está integrado exclusivamente por militares (oficiales y suboficiales) con muy escasa participación de civiles; el grupo de profesores está organizado por civiles con alguna participación de militares, y el grupo de estudiantes está compuesto por civiles con una 
muy escasa participación de militares. Esta marcada división entre los grupos estudiados limita la obtención de los matices que surgen en la interrelación directa entre individuos en su quehacer cotidiano.

Por tal motivo, se utilizó una estructura de 65 preguntas elaboradas con base en la limitada literatura aplicable (Becerra \& Gelvan, 2010; Correa et al., 2013; López-de-Arana et al., 2019; Paulsen, 2018; Stecconi, 2014) y un esquema de respuestas de selección múltiple del tipo Likert de cinco opciones: (1) Deficiente, (2) Aceptable, (3) Satisfactorio, (4) Bueno y (5) Excelente (Armstrong, 1987; Croasmun \& Ostrom, 2011; Joshi et al., 2015). Las preguntas están organizadas en nueve secciones, las cuales corresponden a las denominadas "condiciones de calidad del programa" establecidas por el MEN en la subsección 2, de la sección 3, del capítulo 2 del Decreto 1330 de 2019. Es así como estas secciones buscan explorar los siguientes aspectos: (1) denominación del programa; (2) justificación del programa; (3) aspectos curriculares; (4) organización de actividades académicas y proceso formativo; (5) investigación, innovación y/o creación artística y cultural; (6) relación con el sector externo; (7) profesores; (8) medios educativos, y (9) infraestructura física y tecnológica.

Frente a la aplicación del cuestionario, con base en la percepción de los tres grupos de estudio (directivos, profesores y estudiantes) sobre el nivel de calidad de las nueve condiciones del programa, se buscó elaborar tres hipótesis que pudieran orientar la lectura de los resultados de este primer momento de autoevaluación. No obstante, con el fin de no condicionar la participación en el cuestionario, estas hipótesis se realizaron a través de escenarios de interacción informal de los investigadores con los grupos de estudio, así como de tres grupos focales, que tuvieron una participación inclusiva de entre seis y nueve hombres y mujeres cada uno, donde se introdujeron en forma progresiva a la discusión las nueve condiciones estudiadas (Hamui-Sutton \& Varela-Ruiz, 2013; Prieto \& March, 2002).

Frente a las tres hipótesis establecidas $(\mathrm{H})$, se presumía que los participantes de los tres grupos tendrían una visión diferencial respecto al grado de cercanía con la Esave; esto significa que se suponía que: (H1) el grupo de los directivos tendría una visión bastante positiva de las condiciones de calidad del programa en razón al sentido de pertenencia con la institución y su espíritu de cuerpo (Juncos \& Pomorska, 2014; Manning, 1991). Asimismo, se esperaba que (H2) el cuerpo de profesores tuviera una visión intermedia 
sobre las condiciones de calidad del programa, más propensa a la crítica en razón a su experiencia con otras instituciones educativas e interrelación con los estudiantes (Singhapakdi \& Vitell, 2007; Vitell \& Singhapakdi, 2008). Finalmente, se proyectaba que (H3) el cuerpo de estudiantes expresaría en una forma más enfática las oportunidades de mejora del programa y de la institución (Newcomb, 1943; Reed, 2017).

\section{Resultados}

Las tres hipótesis se probaron verdaderas cuando se examinaron frente a las respuestas que se obtuvieron en los grupos focales. Se demostró que los participantes del cuerpo directivo tuvieron una propensión a ser mucho más propositivos en la evaluación de la calidad de las condiciones de calidad del programa; los profesores tuvieron una visión más neutral, pero propositiva, y los estudiantes evidenciaron una actitud mucho más cercana a la desaprobación de algunos aspectos. Las respuestas obtenidas en los grupos focales se cuantificaron con el fin de proyectar el patrón de respuesta que presumiblemente se replicaría en las respuestas de los grupos estudiados (tabla 3).

Tabla 3. Tendencias de respuestas esperadas en el cuestionario

\begin{tabular}{lccccc}
\hline & Deficiente & Aceptable & Satisfactorio & Bueno & Excelente \\
\hline Directivos & $0,0 \%$ & $10,0 \%$ & $20,0 \%$ & $30,0 \%$ & $40,0 \%$ \\
Profesores & $5,0 \%$ & $20,0 \%$ & $30,0 \%$ & $20,0 \%$ & $25,0 \%$ \\
Estudiantes & $10,0 \%$ & $30,0 \%$ & $40,0 \%$ & $10,0 \%$ & $10,0 \%$ \\
Mediana & $2,5 \%$ & $15,0 \%$ & $25,0 \%$ & $25,0 \%$ & $32,5 \%$ \\
\hline
\end{tabular}

Fuente: elaboración propia.

\section{Denominación del programa}

El artículo 2.5.3.2.3.2.2. del Decreto 1330 de 2019 establece sobre esta condición que la denominación o nombre del programa debe corresponder con "el título que se va a otorgar, el nivel de formación, los contenidos curriculares del programa y el perfil del egresado; lo anterior de conformidad con la normatividad vigente" (MEN, 2019, p. 11). 
Las preguntas que se utilizaron fueron: En una escala de 1 a 5, donde 1 es deficiente y 5 excelente, (a) ¿Cómo evalúa usted la calidad del Proyecto Educativo Institucional (PEI) en relación con el pregrado en Ingeniería Aeronáutica?, (b) ¿Cómo evalúa usted la calidad de la misión y visión institucionales en relación con el pregrado en Ingeniería Aeronáutica?, (c) ¿Cómo evalúa usted la coherencia entre el PEI y las áreas estratégicas de la ESAVE? y (d) ¿Cómo evalúa usted la calidad de la estrategia que usa la EsAve para la divulgación del PeI? Las respuestas obtenidas en forma individual por cada pregunta se detallan en las figuras 8 a 11 .

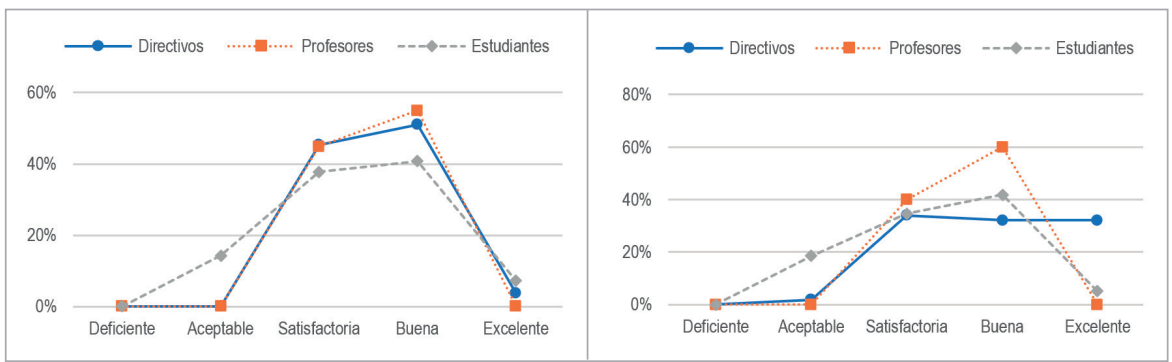

Figura 8. Calidad del Proyecto Educativo Institucional.

Fuente: elaboración propia.

Figura 9. Calidad de la misión y visión institucionales.

Fuente: elaboración propia.

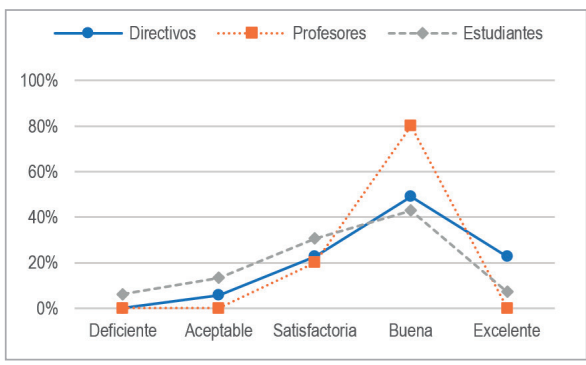

Figura 10. Coherencia del Pei y las áreas estratégicas.

Fuente: elaboración propia.

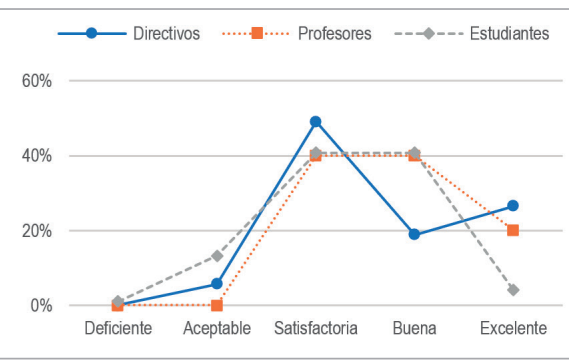

Figura 11. Calidad de la estrategia de divulgación del Pei.

Fuente: elaboración propia.

Los datos consolidados de las preguntas sobre la denominación del programa, utilizando la mediana de las respuestas obtenidas, se grafican en las figuras 12 y 13. Los directivos muestran una propensión a la evaluación de las condiciones mayoritariamente en términos de excelente $(24,5 \%)$, bueno $(40,6 \%)$ y satisfactorio (39,6\%); los profesores centran su opinión en términos de bueno $(575 \%)$ y satisfactorio $(40,0 \%)$; y los estudiantes en 
bueno (41,3\%), satisfactorio (36,3\%) y aceptable (13,8 \%). Por otra parte, la percepción obtenida sobre la calidad de los componentes de esta condición es mucho mayor que la esperada en profesores y directivos en los rangos satisfactorio y bueno, pero se presenta un fenómeno contrario en la percepción de los estudiantes, la cual es inferior a la esperada en todos los rangos de calificación.

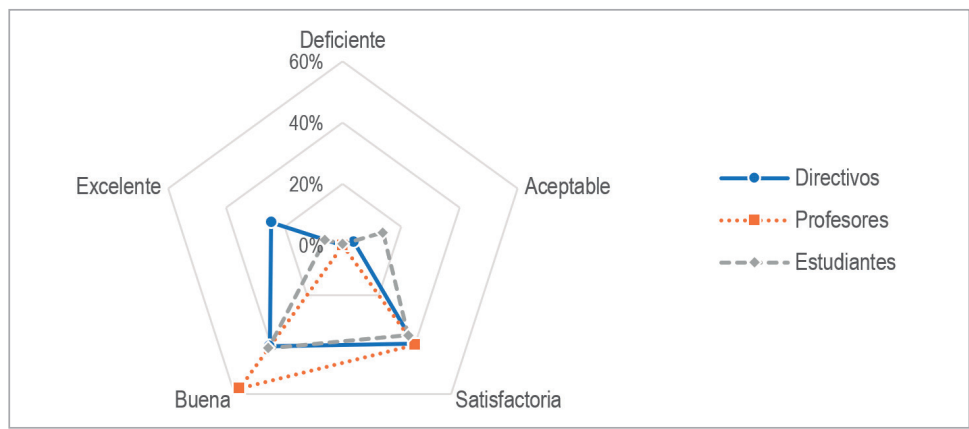

Figura 12. Percepción consolidada sobre la condición "denominación del programa”. Fuente: elaboración propia.

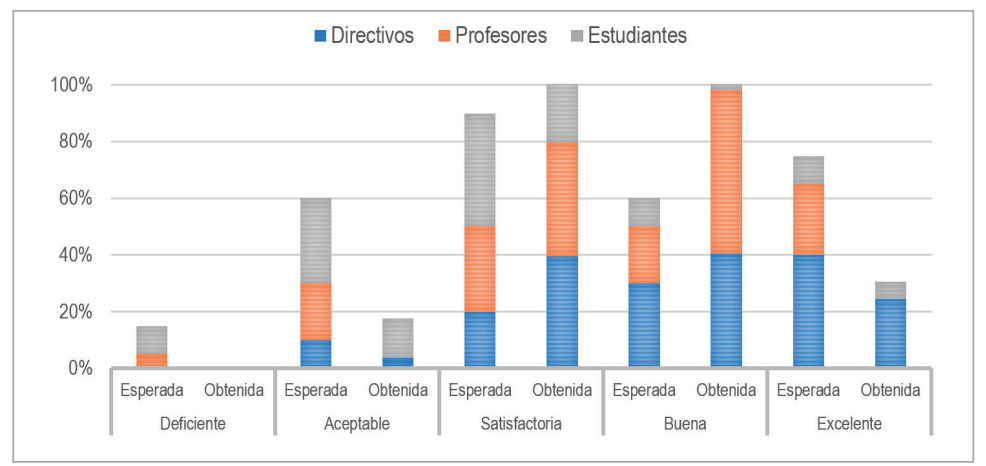

Figura 13. Comparación consolidada entre la percepción esperada y la obtenida sobre la condición "denominación del programa".

Fuente: elaboración propia.

\section{Justificación del programa}

El artículo 2.5.3.2.3.2.3. del Decreto 1330 de 2019 establece sobre esta condición que debe existir una justificación "que sustente el contenido curricular, los perfiles de egreso y la(s) modalidad(es), en que se desea ofrecer el programa para que este sea pertinente al desarrollo social, cultural, ambiental, económico y científico, frente a las necesidades del país y la región” (Men, 2019, p. 12). 
Las preguntas que se utilizaron fueron: en una escala de 1 a 5, donde 1 es deficiente y 5 excelente, (a) ¿Cómo evalúa usted la proyección de la profesión de ingeniería aeronáutica en el ámbito local, regional, nacional e internacional?, (b) ¿Cómo evalúa usted la calidad del proceso de selección e ingreso de estudiantes?, (c) ¿Cómo evalúa usted la calidad de la difusión del proceso de admisión en medios de comunicación? y $(\mathrm{d})$ ¿Cómo evalúa usted el nivel de exigencia y rigurosidad para el ingreso al programa? Las respuestas obtenidas en forma individual por cada pregunta se detallan en las figuras 14 a 17 .

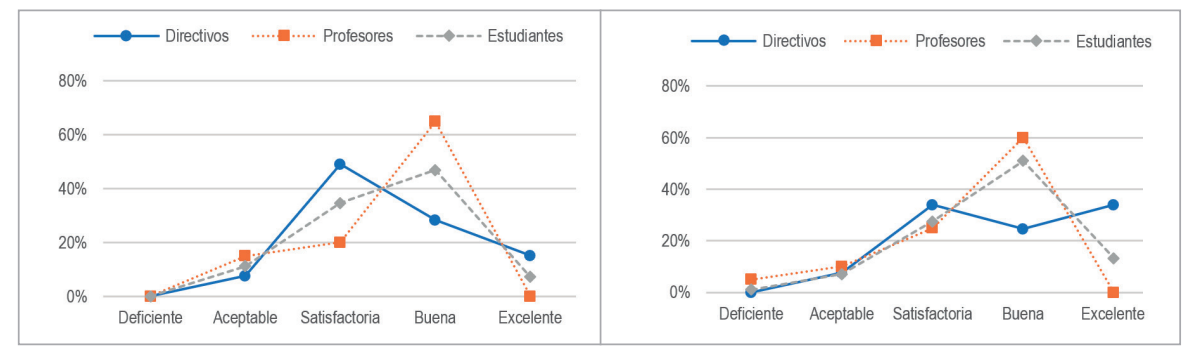

Figura 14. Proyección del programa de Ingeniería Aeronáutica.

Fuente: elaboración propia.

Figura 15. Calidad del proceso de selección e ingreso de estudiantes.

Fuente: elaboración propia.

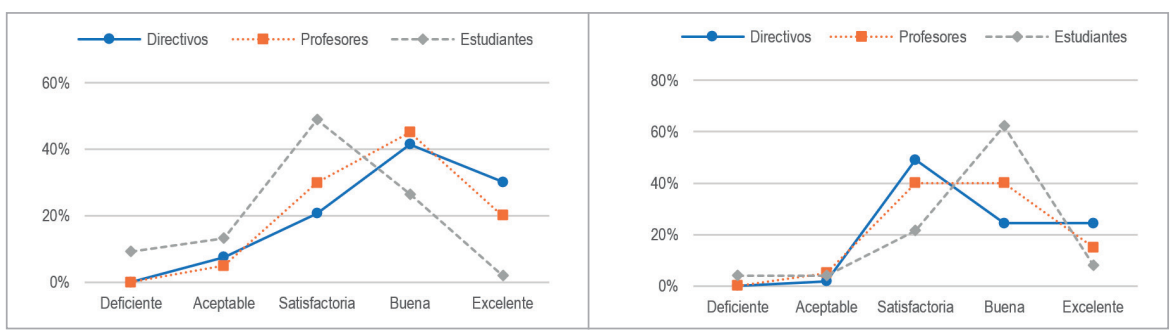

Figura 16. Calidad de la difusión del proceso de admisión en medios de comunicación.

Figura 17. Nivel de exigencia y rigurosidad para el ingreso al programa.

Fuente: elaboración propia. Fuente: elaboración propia.

Los datos consolidados de las preguntas sobre la justificación del programa, utilizando la mediana de las respuestas obtenidas, se grafican en las figuras 18 y 19. Los directivos muestran una tendencia a percibir estas condiciones principalmente en términos de excelente $(27,4 \%)$, bueno $(26,4 \%)$ y satisfactorio (41,5\%); los profesores centran su opinión en términos de bueno $(52,5 \%)$ y satisfactorio $(27,5 \%)$, y los estudiantes en bueno $(49,0 \%)$ y satisfactorio $(31,1 \%)$. Por otra parte, la percepción obtenida sobre la calidad de 
los componentes de esta condición es mucho mayor que la esperada en directivos y profesores en los rangos satisfactorio y bueno, respectivamente, pero se presenta un fenómeno contrario en la percepción de los estudiantes, la cual es inferior a la esperada en todos los rangos de calificación, con excepción del rango bueno.

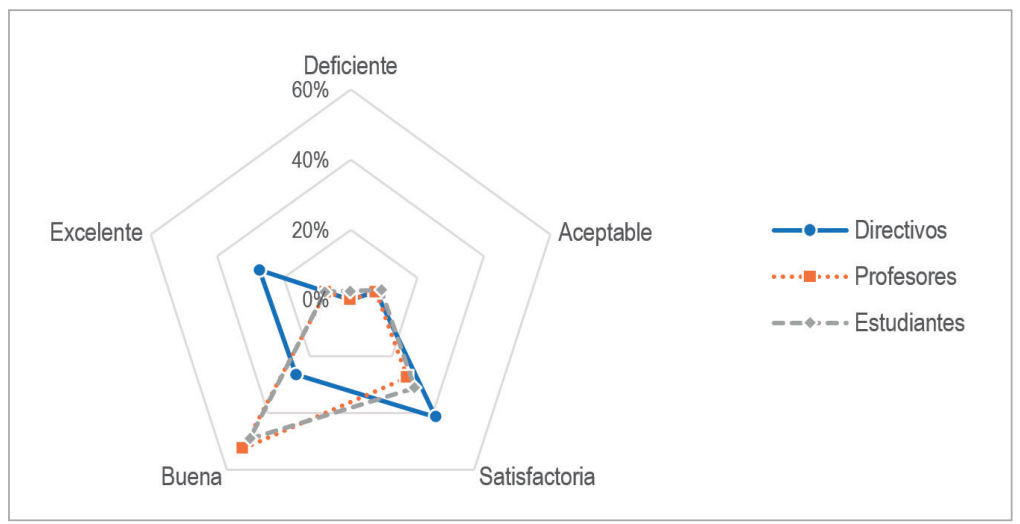

Figura 18. Percepción consolidada sobre la condición “justificación del programa”. Fuente: elaboración propia.

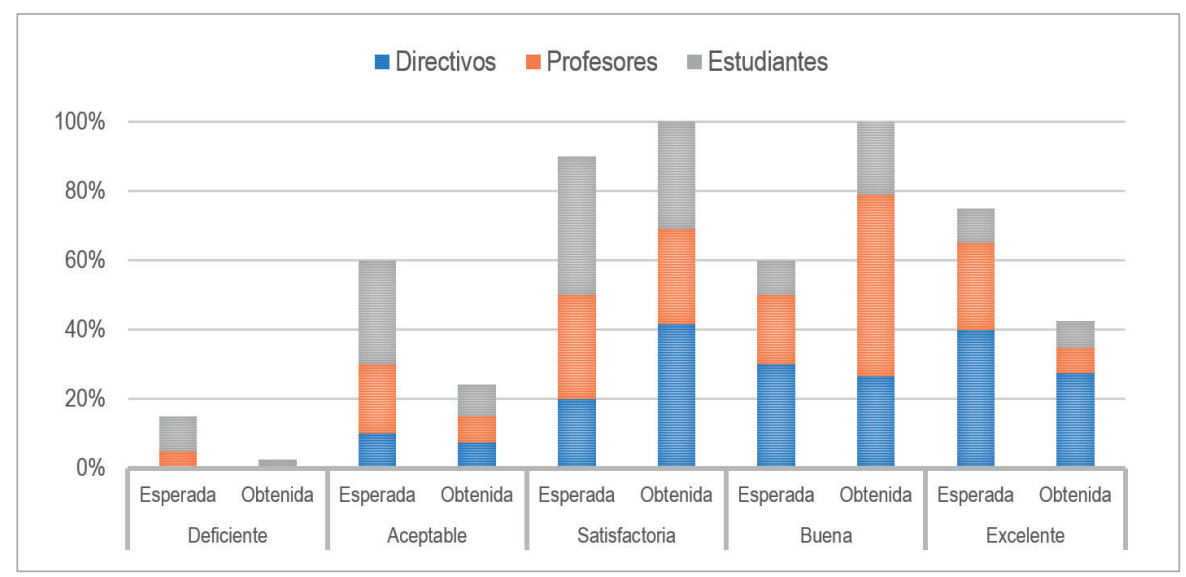

Figura 19. Comparación consolidada entre la percepción esperada y la obtenida sobre la condición "justificación del programa”.

Fuente: elaboración propia.

\section{Aspectos curriculares}

El artículo 2.5.3.2.3.2.4. del Decreto 1330 de 2019 establece sobre esta condición que la institución debe "diseñar el contenido curricular del programa 
según el área de conocimiento y en coherencia con las modalidades (presencial, a distancia, virtual, dual u otros desarrollos que combinen e integren las anteriores modalidades), los niveles de formación, su naturaleza jurídica, tipología e identidad institucional" (MEN, 2019, p. 12).

Las preguntas que se utilizaron fueron: En una escala de 1 a 5 , donde 1 es deficiente y 5 excelente, (a) ¿Cómo evalúa usted la calidad de las políticas de flexibilidad curricular?, (b) ¿Cómo evalúa usted la calidad de las políticas para la apropiación de idiomas extranjeros y Tic?, (c) ¿Cómo evalúa usted la disponibilidad de recursos informáticos y de comunicación?, (d) ¿Cómo evalúa usted la existencia y disponibilidad de recursos bibliográficos?, (e) ¿Cómo evalúa usted la participación de los estudiantes en las decisiones de la EsAvE?, (f) ¿Cómo evalúa usted la aplicación de estrategias para la permanencia y evitar la deserción estudiantil? y (g) ¿Cómo evalúa usted la calidad de las políticas institucionales de estímulos para los estudiantes? Las respuestas obtenidas en forma individual por cada pregunta se detallan en las figuras 20 a 26.

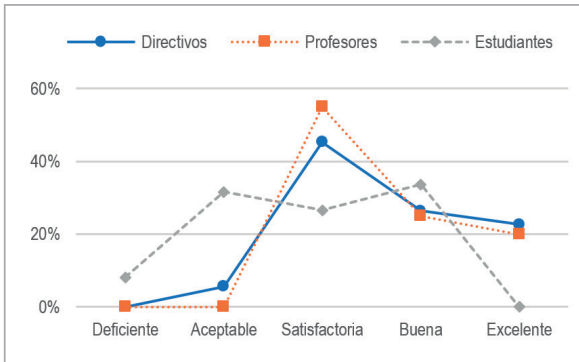

Figura 20. Calidad de las políticas de flexibilidad curricular.

Fuente: elaboración propia.

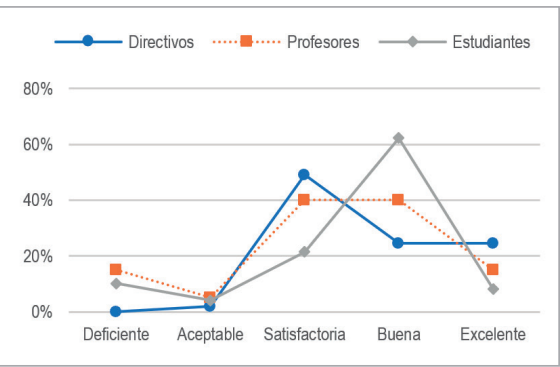

Figura 21. Calidad de las políticas para la apropiación de idiomas extranjeros y Tic. Fuente: elaboración propia.

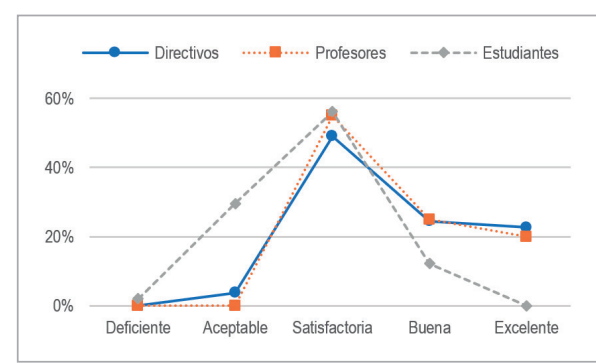

Figura 22. Disponibilidad de recursos informáticos y de comunicación. Fuente: elaboración propia.

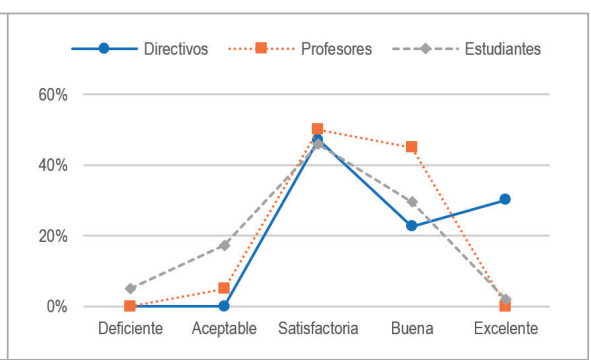

Figura 23. Existencia y disponibilidad de recursos bibliográficos.

Fuente: elaboración propia. 


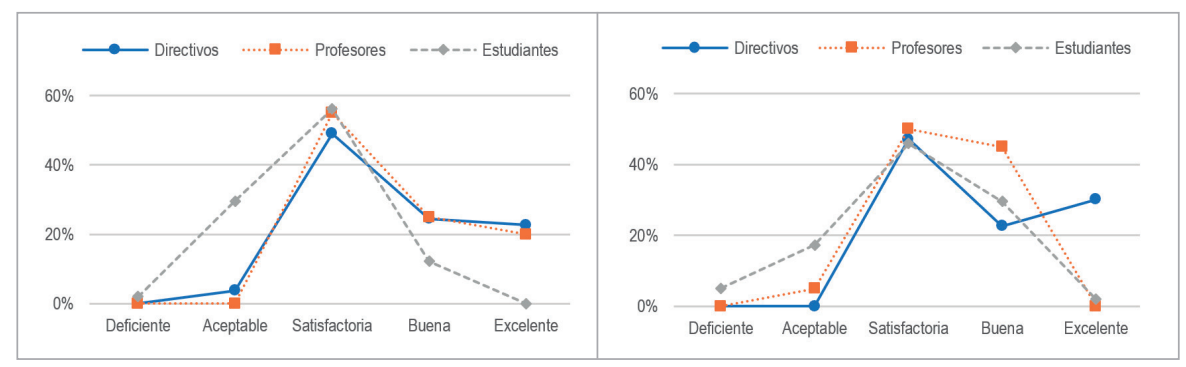

Figura 24. Participación de los estudiantes en las decisiones de la Esave.

Figura 25. Aplicación de estrategias para la Fuente: elaboración propia. permanencia (evitar la deserción). Fuente: elaboración propia.

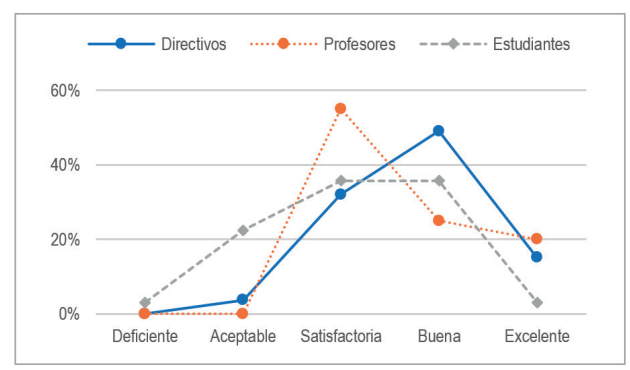

Figura 26. Calidad de las políticas institucionales de estímulos para los estudiantes.

Fuente: elaboración propia.

Los datos consolidados de las preguntas sobre los aspectos curriculares, utilizando la mediana de las respuestas obtenidas, se grafican en las figuras 27 y 28. Los directivos muestran una tendencia a percibir estas condiciones principalmente en términos de bueno $(24,5 \%)$ y satisfactorio $(47,2 \%)$; los profesores centran su opinión en términos de bueno $(35,0 \%)$ y satisfactorio $(50,0 \%)$; y los estudiantes en bueno $(30,6 \%)$ y satisfactorio (36,7 \%). Por otra parte, la percepción obtenida sobre la calidad de los componentes de esta condición es mucho mayor que la esperada en directivos y profesores en el rango satisfactorio, pero se presenta un fenómeno contrario en la percepción de los estudiantes, la cual es inferior a la esperada en todos los rangos de calificación, con excepción del rango bueno. 


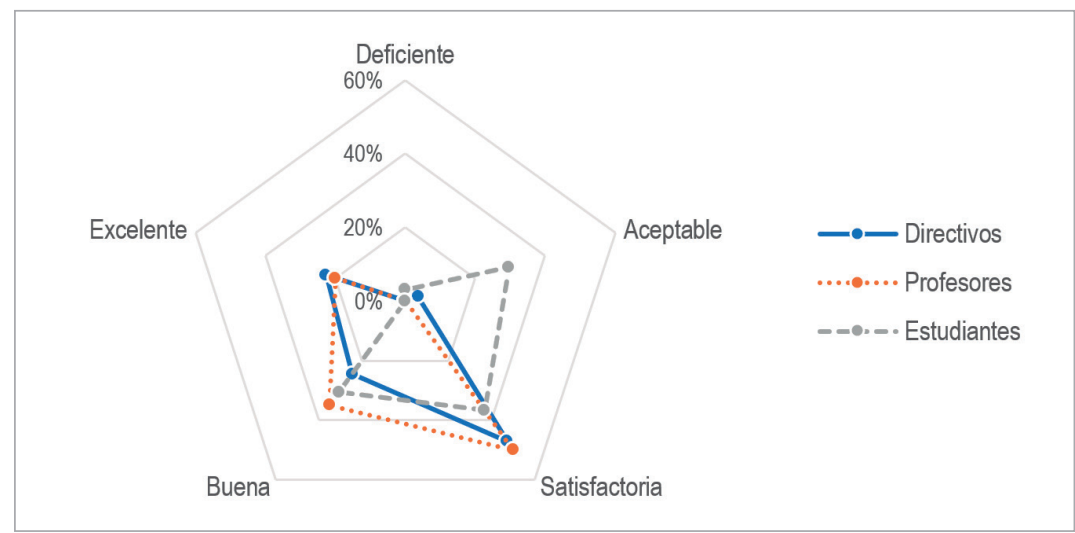

Figura 27. Percepción consolidada sobre la condición "aspectos curriculares". Fuente: elaboración propia.

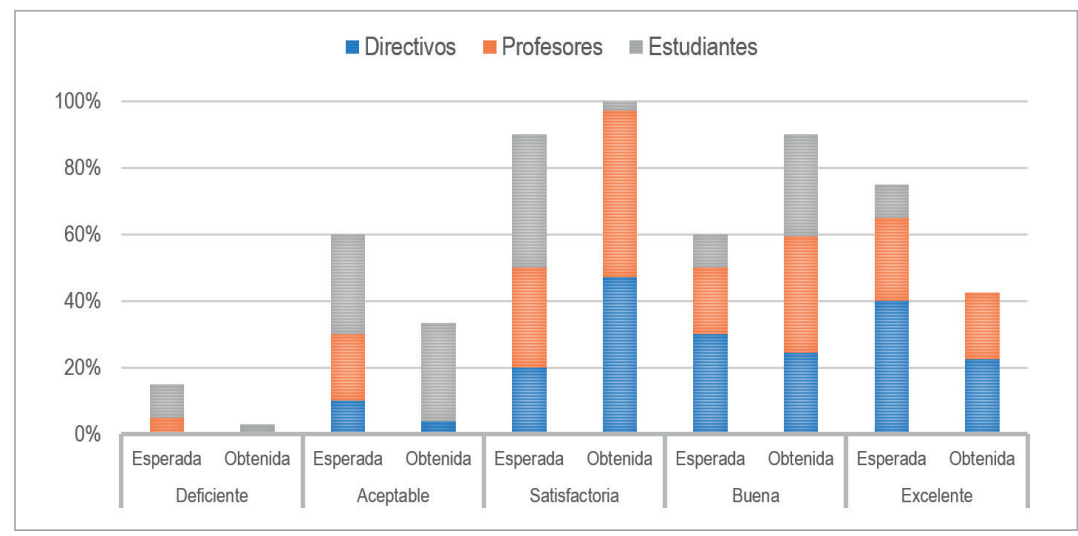

Figura 28. Comparación consolidada entre la percepción esperada y la obtenida sobre la condición "aspectos curriculares".

Fuente: elaboración propia.

\section{Organización de actividades académicas y proceso formativo}

El artículo 2.5.3.2.3.2.5. del Decreto 1330 de 2019 establece sobre esta condición que la institución debe "establecer en el programa, la organización de las actividades y la interacción de las mismas, de acuerdo con el diseño y el contenido curricular, en coherencia con las modalidades, los niveles de formación, la naturaleza jurídica, la tipología y la identidad institucional" (Men, 2019, p. 13).

Las preguntas que se utilizaron fueron: En una escala de 1 a 5 , donde 1 es deficiente y 5 excelente, (a) ¿Cómo evalúa usted la calidad de la estructura y las 
actividades académicas del programa?, (b) ¿Cómo evalúa usted la calidad del proceso formativo? y (c) ¿Cómo evalúa usted la participación en la planeación y el desarrollo de las actividades académicas? Las respuestas obtenidas en forma individual por cada pregunta se detallan en las figuras 29 a 31 .

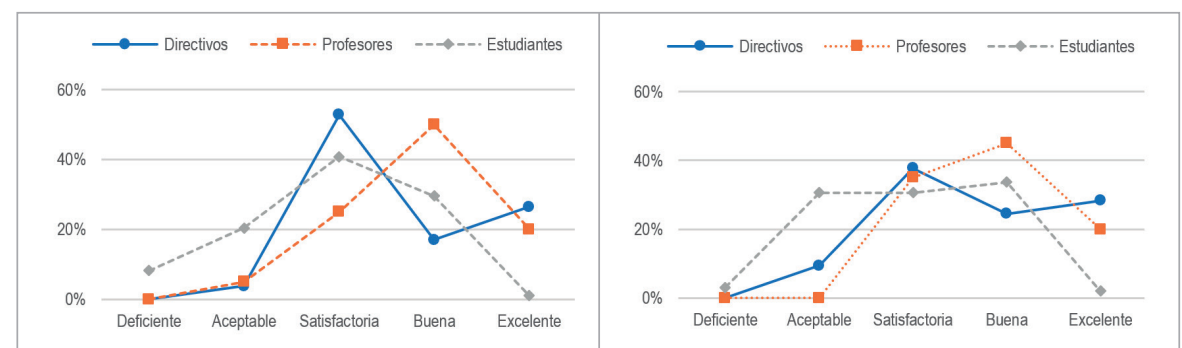

Figura 29. Calidad de la estructura y actividades académicas del programa.

Figura 30. Calidad del proceso formativo. Fuente: elaboración propia. Fuente: elaboración propia.

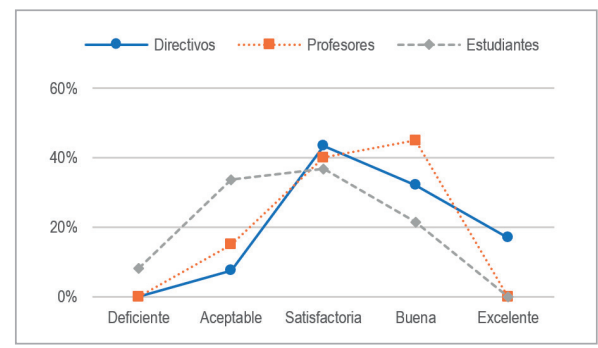

Figura 31. Participación en la planeación y el desarrollo de las actividades académicas.

Fuente: elaboración propia.

Los datos consolidados de las preguntas sobre la organización de actividades académicas y proceso formativo, utilizando la mediana de las respuestas obtenidas, se grafican en las figuras 32 y 33. Los directivos muestran una tendencia a percibir estas condiciones principalmente en términos de excelente $(26,4 \%)$ y satisfactorio (43,4\%); los profesores centran su opinión en términos de bueno $(45,0 \%)$ y satisfactorio $(35,0 \%)$, y los estudiantes en satisfactorio $(36,7 \%)$ y aceptable $(30,6 \%)$. Por otra parte, la percepción obtenida sobre la calidad de los componentes de esta condición es mucho mayor que la esperada en directivos y profesores en el rango satisfactorio, pero se presenta un fenómeno contrario en la percepción de los estudiantes, la cual es inferior a la esperada en todos los rangos de calificación. 


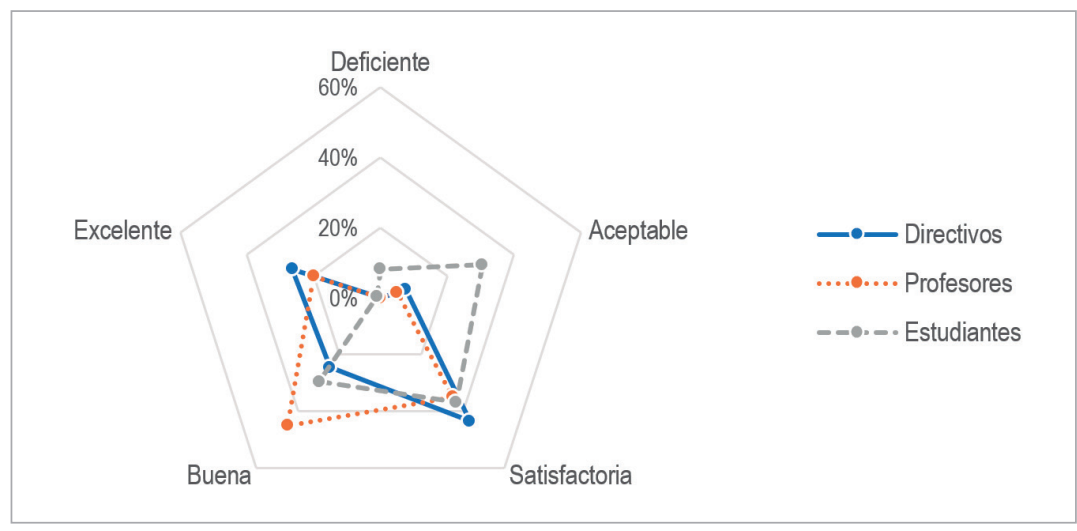

Figura 32. Percepción consolidada sobre la condición "organización de actividades académicas y proceso formativo".

Fuente: elaboración propia.

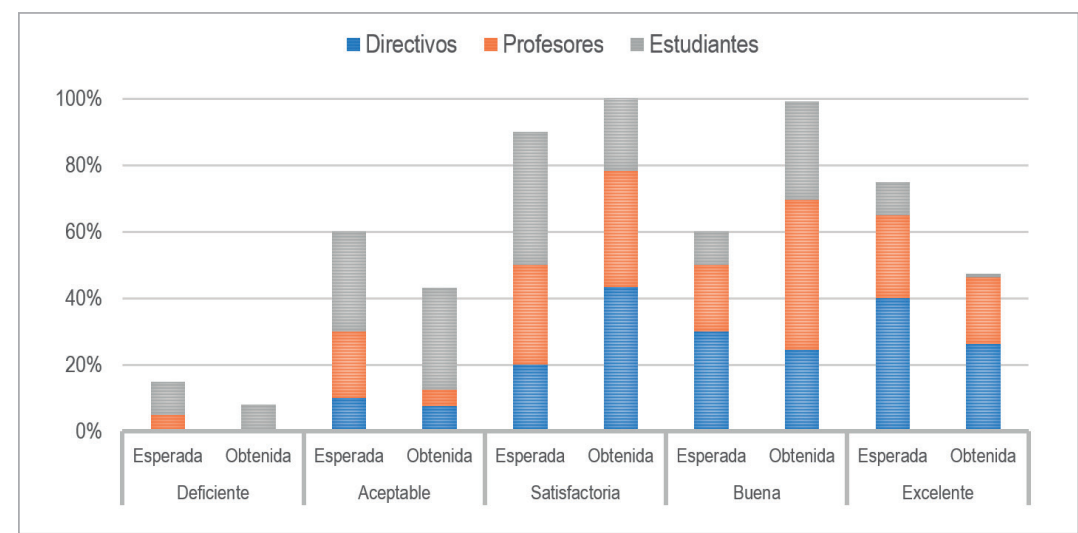

Figura 33. Comparación consolidada entre la percepción esperada y la obtenida sobre la condición "organización de actividades académicas y proceso formativo".

Fuente: elaboración propia.

\section{Investigación, innovación y/o creación artística y cultural}

El artículo 2.5.3.2.3.2.6. del Decreto 1330 de 2019 establece sobre esta condición que "según la declaración explícita que realice el programa en relación con la incorporación de la investigación para el desarrollo de conocimiento, el programa deberá definir las áreas, líneas o temáticas de investigación en las que se enfocarán los esfuerzos y proyectos" (Men, 2019, p. 13).

Las preguntas que se utilizaron fueron: En una escala de 1 a 5 , donde 1 es deficiente y 5 excelente, (a) ¿Cómo evalúa usted la calidad de las políticas de 
incentivo a la creación artística y cultural?, (b) ¿Cómo evalúa usted la calidad de la divulgación de las investigaciones desarrolladas en la Esave?, (c) ¿Cómo evalúa usted el nivel de apoyo y de recursos institucionales para la investigación formativa? y (d) ¿Cómo evalúa usted el nivel de acercamiento al sector productivo de la aeronáutica? Las respuestas obtenidas en forma individual por cada pregunta se detallan en las figuras 34 a 37.

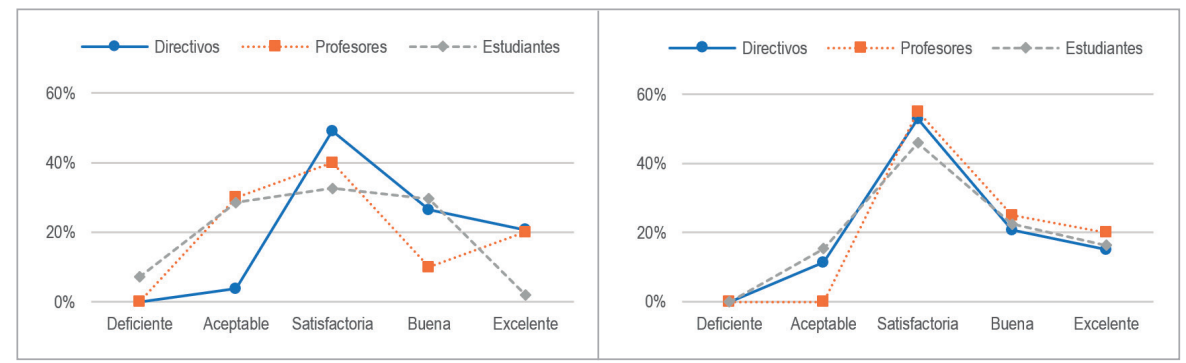

Figura 34. Calidad de las políticas de incentivo a la creación artística y cultural. Fuente: elaboración propia.
Figura 35. Calidad de la divulgación de las investigaciones desarrolladas en la EsAvE. Fuente: elaboración propia.

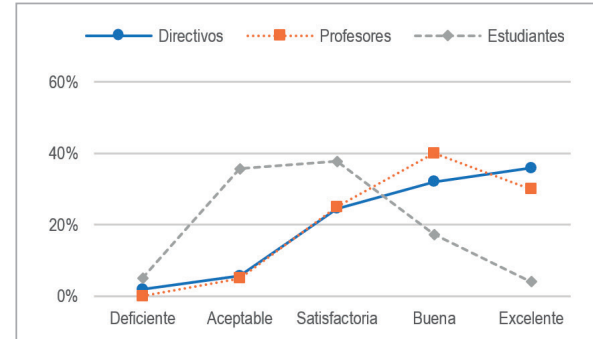

Figura 36. Nivel de apoyo y de recursos institucionales para la investigación formativa.

Fuente: elaboración propia.

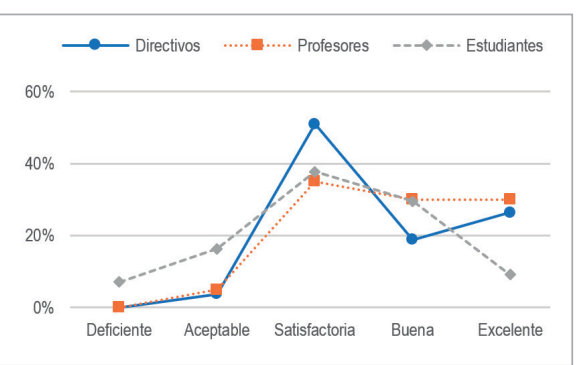

Figura 37. Nivel de acercamiento al sector productivo de la aeronáutica. Fuente: elaboración propia.

Los datos consolidados de las preguntas sobre la investigación, innovación y/o creación artística y cultural, utilizando la mediana de las respuestas obtenidas, se grafican en las figuras 38 y 39. Los directivos muestran una tendencia a percibir estas condiciones principalmente en términos de bueno $(23,6 \%)$ y satisfactorio (50,0\%); los profesores centran su opinión en términos de bueno $(27,5 \%)$ y satisfactorio (37,5\%), y los estudiantes en bueno (26,0 \%) y satisfactorio $(37,8 \%)$. Por otra parte, la percepción obtenida sobre la calidad de los componentes de esta condición es mucho mayor que la esperada en directivos 
en el rango satisfactorio y en los profesores en los rangos bueno y satisfactorio, pero se presenta un fenómeno contrario en la percepción de los estudiantes, la cual es inferior a la esperada en todos los rangos de calificación, con excepción del rango bueno.

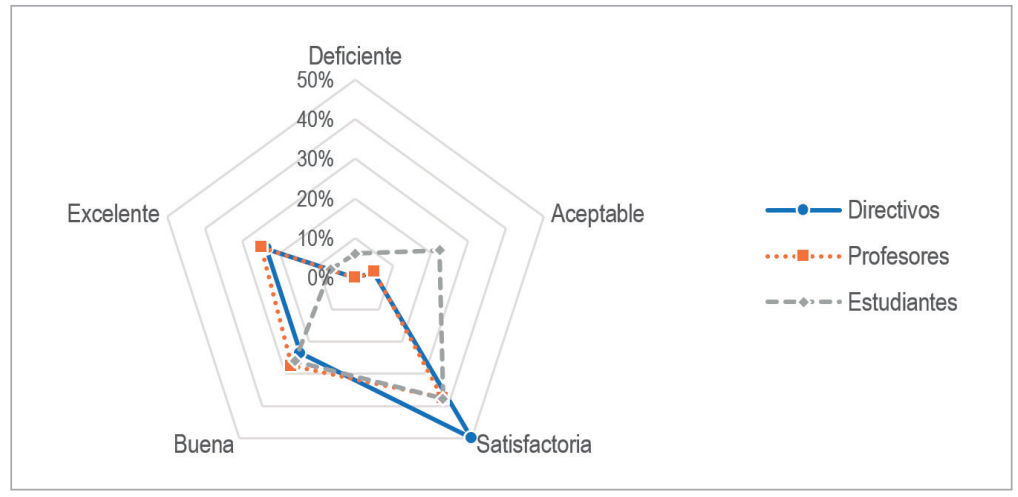

Figura 38. Percepción consolidada sobre la condición “investigación, innovación y/o creación artística y cultural”.

Fuente: elaboración propia.

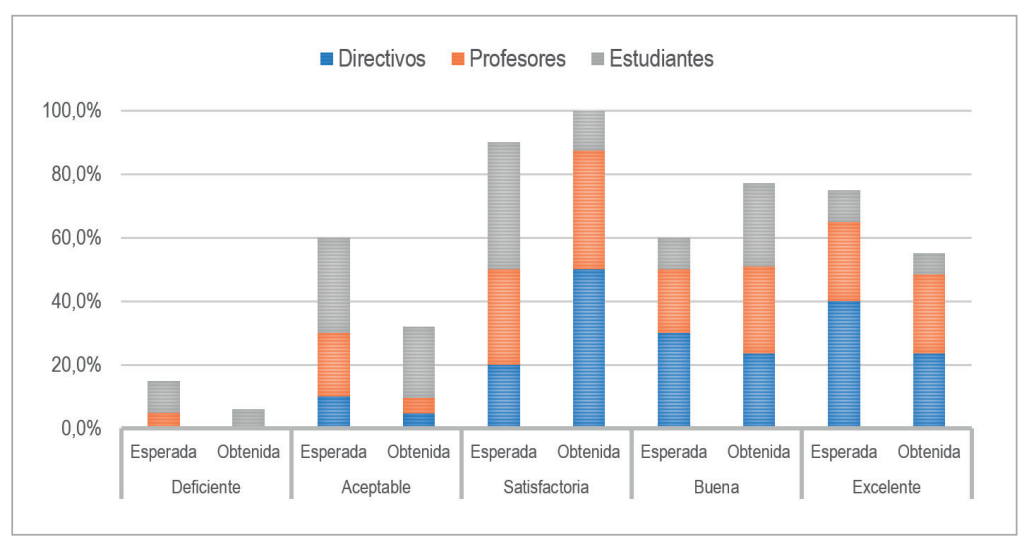

Figura 39. Comparación consolidada entre la percepción esperada y la obtenida sobre la condición "investigación, innovación y/o creación artística y cultural”.

\section{Relación con el sector externo}

El artículo 2.5.3.2.3.2.7. del Decreto 1330 de 2019 establece sobre esta condición que la institución debe "establecer para el programa, los mecanismos y estrategias para lograr la vinculación de la comunidad y el sector productivo, social, cultural, público y privado, en coherencia con las modalidades, el nivel 
de formación del programa, la naturaleza jurídica de la institución, la tipología e identidad institucional” (Men, 2019, p. 14).

Las preguntas que se utilizaron fueron: En una escala de 1 a 5 , donde 1 es deficiente y 5 excelente, (a) ¿Cómo evalúa usted la calidad de la política institucional de internacionalización?, (b) ¿Cómo evalúa usted la calidad de la interacción académica de la Esave?, (c) ¿Cómo evalúa usted la calidad de los programas, servicios y estrategias de bienestar institucional? y (d) ¿Cómo evalúa usted la calidad y el impacto de los servicios de bienestar a la comunidad académica? Las respuestas obtenidas en forma individual por cada pregunta se detallan en las figuras 40 a 43 .

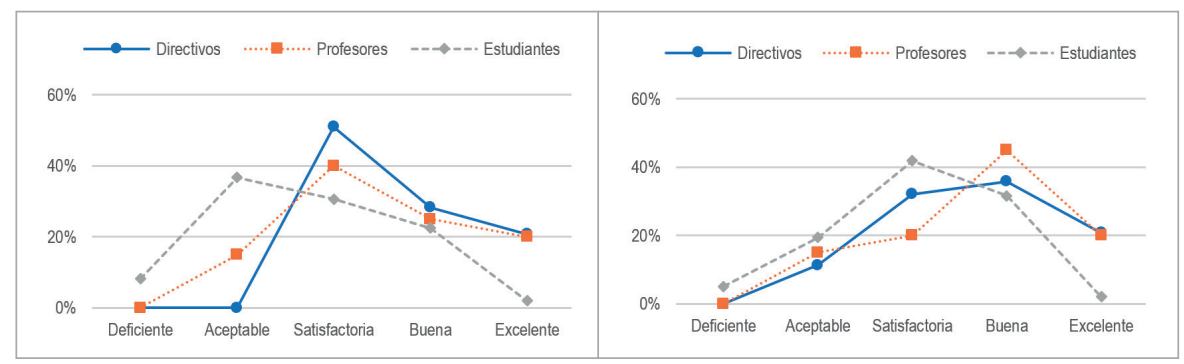

Figura 40. Calidad de la política institucional de internacionalización. Fuente: elaboración propia.
Figura 41. Calidad de la interacción académica de la Esave.

Fuente: elaboración propia.

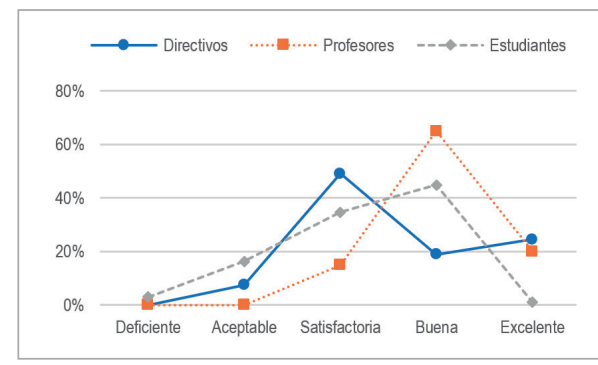

Figura 42. Calidad de los programas, servicios y estrategias de bienestar institucional. Fuente: elaboración propia.

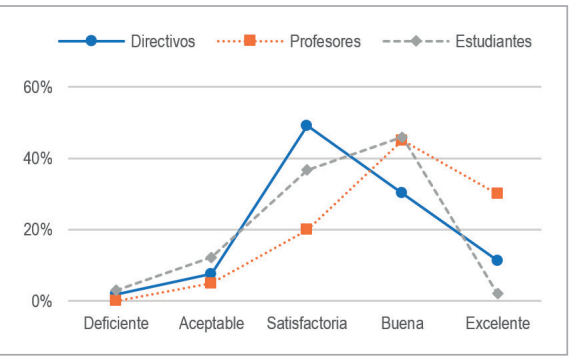

Figura 43. Calidad y el impacto de los servicios de bienestar a la comunidad académica. Fuente: elaboración propia.

Los datos consolidados de las preguntas sobre la relación con el sector externo, utilizando la mediana de las respuestas obtenidas, se grafican en las figuras 44 y 45 . Los directivos muestran una tendencia a percibir estas condiciones principalmente en términos de bueno (29,2 \%) y satisfactorio (49,1\%); los profesores centran su opinión en términos de bueno $(45,0 \%)$ y satisfactorio $(20,0 \%)$, y los estudiantes en bueno $(38,3 \%)$ y satisfactorio $(35,7 \%)$. 
Por otra parte, la percepción obtenida sobre la calidad de los componentes de esta condición es mucho mayor que la esperada en directivos en el rango satisfactorio y en los profesores en el rango bueno, pero se presenta un fenómeno contrario en la percepción de los estudiantes, la cual es inferior a la esperada en todos los rangos de calificación, con excepción del rango bueno.

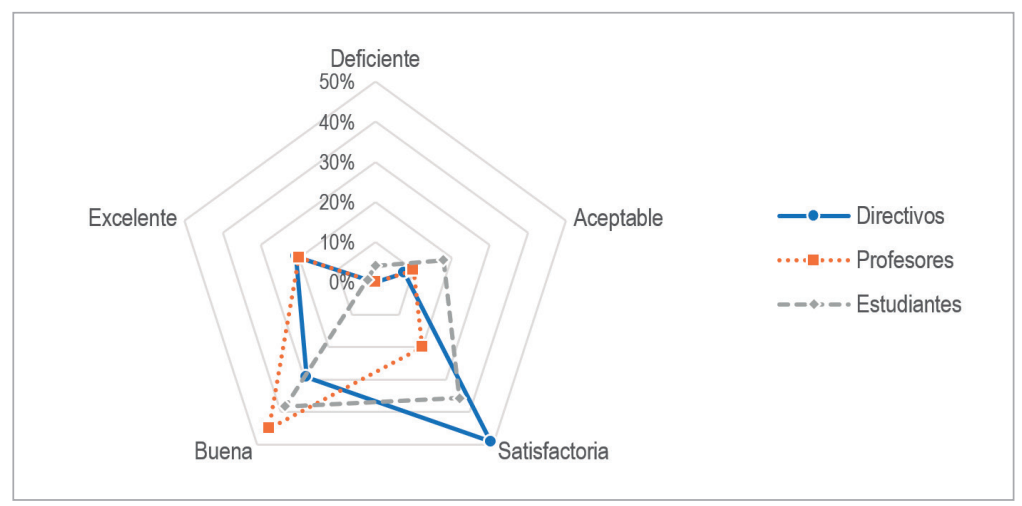

Figura 44. Percepción consolidada sobre la condición "relación con el sector externo". Fuente: elaboración propia.

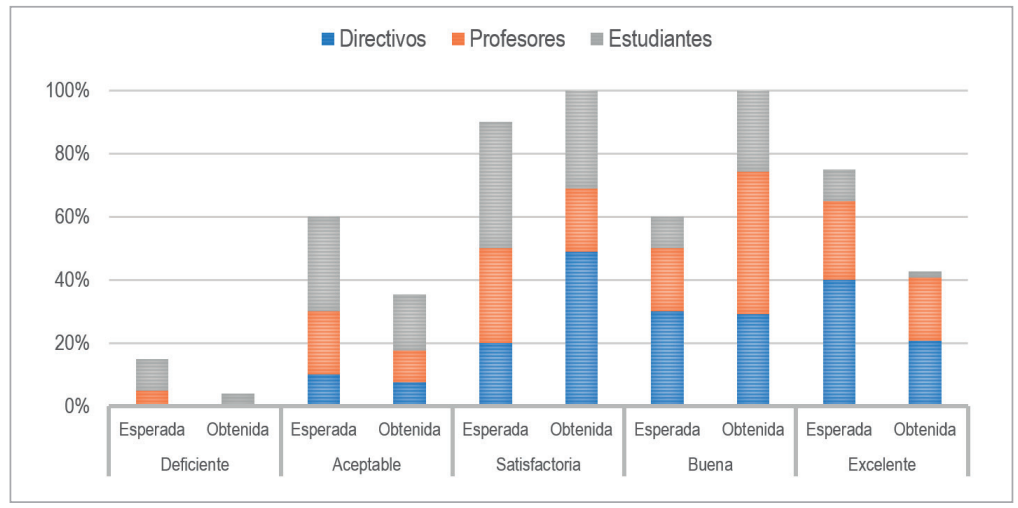

Figura 45. Comparación consolidada entre la percepción esperada y la obtenida sobre la condición "relación con el sector externo".

Fuente: elaboración propia.

\section{Profesores}

El artículo 2.5.3.2.3.2.8. del Decreto 1330 de 2019 establece sobre esta condición que la institución debe "especificar para el programa un grupo de profesores que, en número, desarrollo pedagógico, nivel de formación, expe- 
riencia laboral, vinculación y dedicación, le permitan atender adecuadamente el proceso formativo, las funciones de docencia, investigación y extensión, en coherencia con las modalidades (presencial, a distancia, virtual, dual u otros desarrollos que combinen e integren las anteriores modalidades), el nivel de formación del programa, la naturaleza jurídica de la institución, la tipología e identidad institucional” (Men, 2019, p. 14).

Las preguntas que se utilizaron fueron: En una escala de 1 a 5 , donde 1 es deficiente y 5 excelente, (a) ¿Cómo evalúa usted la confianza frente a los procedimientos de selección, permanencia y evaluación docente?, (b) ¿Cómo evalúa usted la calidad de las estrategias de la EsAve para propiciar la permanencia de los profesores?, (c) ¿Cómo evalúa usted la calidad de la política de reconocimientos e incentivos a la labor docente? y (d) ¿Cómo evalúa usted la coherencia entre la remuneración a la labor docente y los méritos profesionales? Las respuestas obtenidas en forma individual por cada pregunta se detallan en las figuras 46 a 49 .

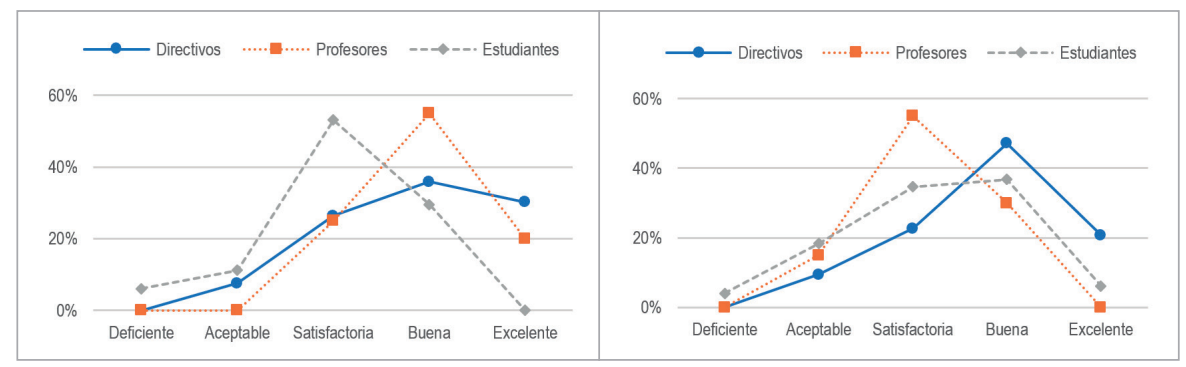

Figura 46. Confianza frente a los procedimientos de selección, permanencia y evaluación docente.

Fuente: elaboración propia.

Figura 47. Calidad de las estrategias de la EsAvE para propiciar la permanencia de los profesores. Fuente: elaboración propia.

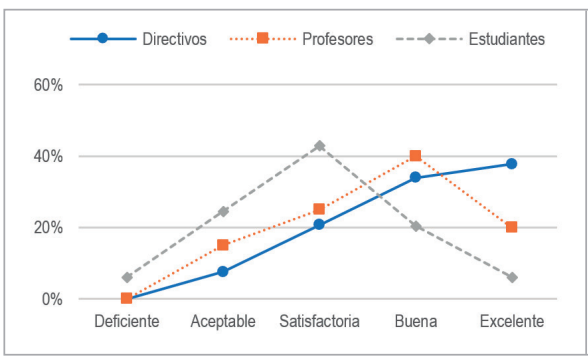

Figura 48. Calidad de la política de reconocimientos e incentivos a la labor docente. Fuente: elaboración propia.

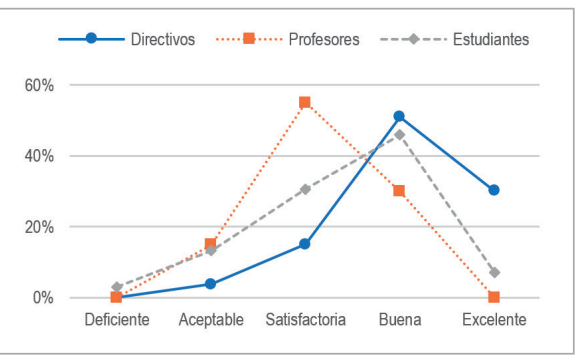

Figura 49. Coherencia entre la remuneración a la labor docente y los méritos profesionales. Fuente: elaboración propia. 
Los datos consolidados de las preguntas sobre los profesores, utilizando la mediana de las respuestas obtenidas, se grafican en las figuras 50 y 51. Los directivos muestran una tendencia a percibir estas condiciones principalmente en términos de excelente $(30,2 \%)$ y bueno (41,5\%); los profesores centran su opinión en términos de bueno $(35,0 \%)$ y satisfactorio (40,0 \%); y los estudiantes en bueno $(33,2 \%)$ y satisfactorio $(38,8 \%)$. Por otra parte, la percepción obtenida sobre la calidad de los componentes de esta condición es mucho mayor que la esperada en directivos y profesores en el rango bueno y satisfactorio, pero se presenta un fenómeno contrario en la percepción de los estudiantes, la cual es inferior a la esperada en todos los rangos de calificación.

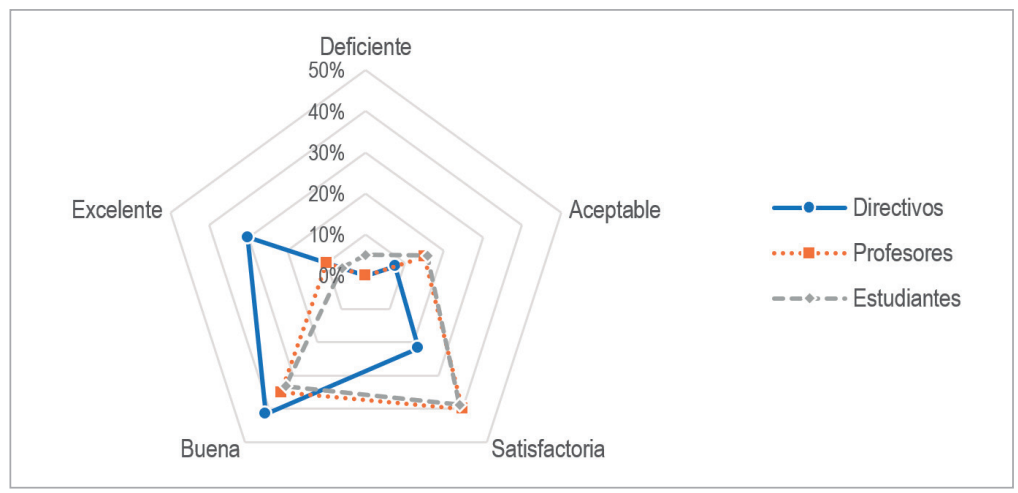

Figura 50. Percepción consolidada sobre la condición "profesores".

Fuente: elaboración propia.

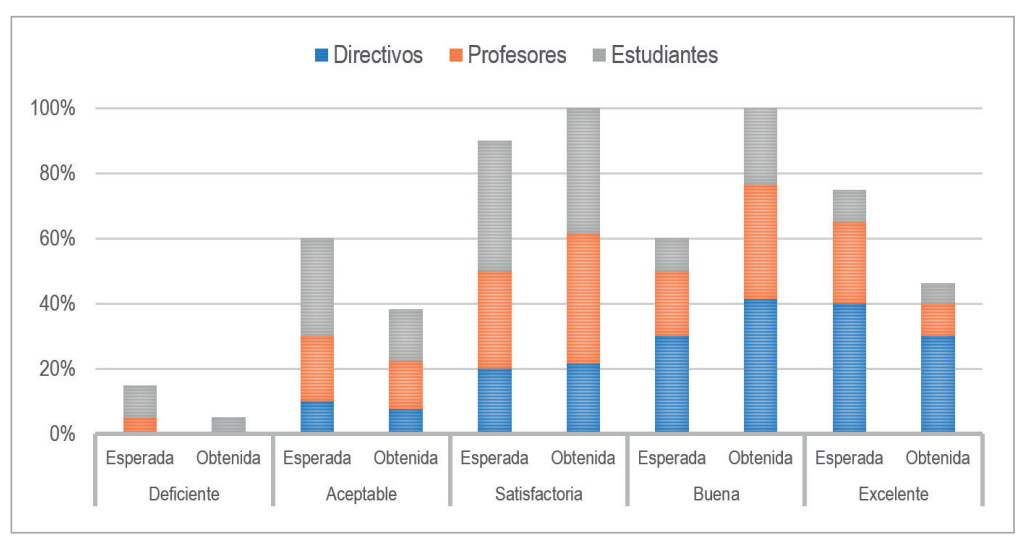

Figura 51. Comparación consolidada entre la percepción esperada y la obtenida sobre la condición "profesores".

Fuente: elaboración propia. 


\section{Medios educativos}

El artículo 2.5.3.2.3.2.9. del Decreto 1330 de 2019 establece sobre esta condición que la institución debe "contar con la dotación de los ambientes físicos y/o virtuales de aprendizaje que incorporan equipos, mobiliario, plataformas tecnológicas, sistemas informáticos o los que hagan sus veces, recursos bibliográficos físicos y digitales, bases de datos, recursos de aprendizaje e información, entre otros, que atienden los procesos formativos, el desarrollo de la investigación y la extensión" (MeN, 2019, p. 14).

Las preguntas que se utilizaron fueron: En una escala de 1 a 5, donde 1 es deficiente y 5 excelente, (a) ¿Cómo evalúa usted la calidad, cantidad, pertinencia y actualización de material bibliográfico?, (b) ¿Cómo evalúa usted la calidad en la atención, horarios y servicios de biblioteca?, (c) ¿Cómo evalúa usted la calidad de los recursos de apoyo didáctico de la Esave? y (d) ¿Cómo evalúa usted la calidad de los escenarios de práctica del programa? Las respuestas obtenidas en forma individual por cada pregunta se detallan en las figuras 52 a 55 .

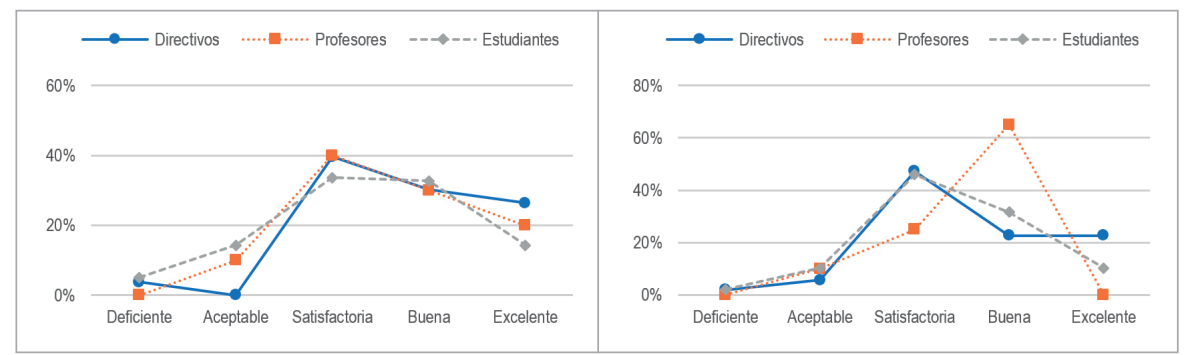

Figura 52. Calidad, cantidad, pertinencia y actualización de material bibliográfico.

Fuente: elaboración propia.

Figura 53. Calidad en la atención, horarios y servicios de biblioteca.

Fuente: elaboración propia.

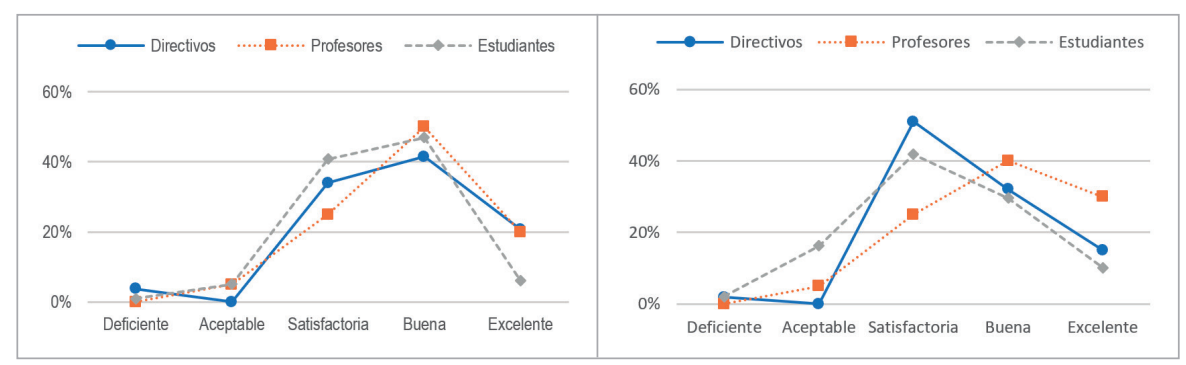

Figura 54. Calidad de los recursos de apoyo didáctico de la EsAVE.

Fuente: elaboración propia.

Figura 55. Calidad de los escenarios de práctica del programa.

Fuente: elaboración propia. 
Los datos consolidados de las preguntas sobre los medios educativos, utilizando la mediana de las respuestas obtenidas, se grafican en las figuras 56 y 57. Los directivos muestran una tendencia a percibir estas condiciones principalmente en términos de bueno $(31,1 \%)$ y satisfactorio $(43,4 \%)$; los profesores centran su opinión en términos de bueno $(45,0 \%)$ y satisfactorio $(25,0 \%)$, y los estudiantes en bueno $(32,1 \%)$ y satisfactorio (41,3\%). Por otra parte, la percepción obtenida sobre la calidad de los componentes de esta condición es mucho mayor que la esperada en directivos en el rango bueno y satisfactorio, y profesores en el rango bueno, pero se presenta un fenómeno contrario en la percepción de los estudiantes, la cual es inferior a la esperada en todos los rangos de calificación, con excepción del rango bueno.

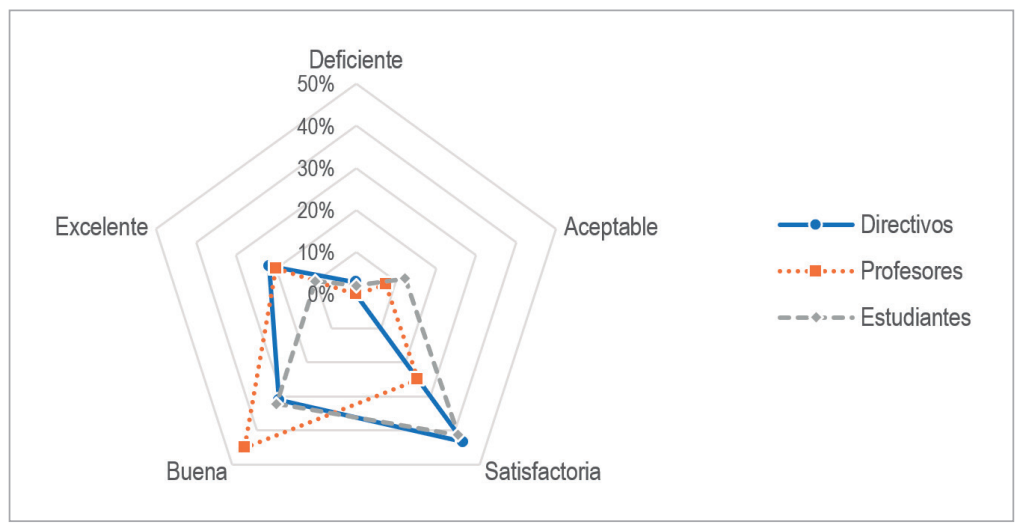

Figura 56. Percepción consolidada sobre la condición "medios educativos". Fuente: elaboración propia.

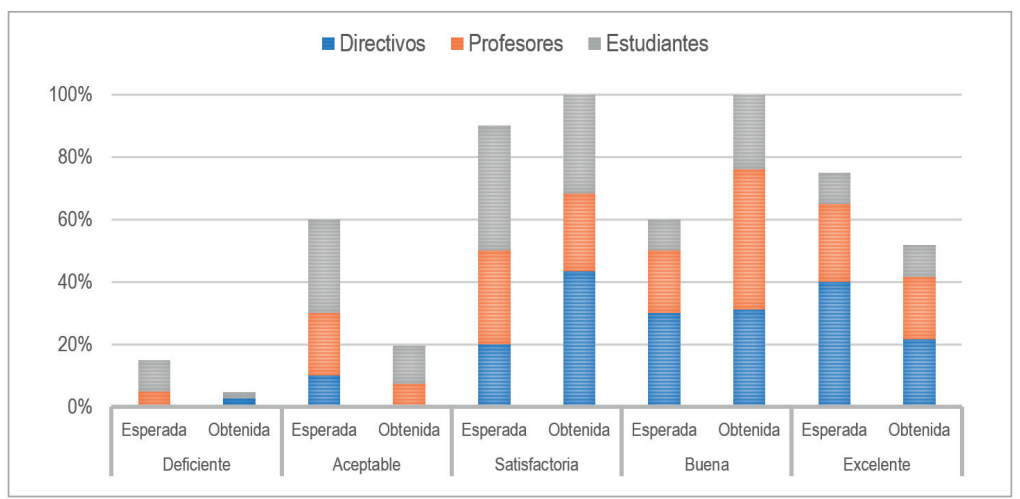

Figura 57. Comparación consolidada entre la percepción esperada y la obtenida sobre la condición "medios educativos".

Fuente: elaboración propia. 


\section{Infraestructura física y tecnológica}

El artículo 2.5.3.2.3.2.10. del Decreto 1330 de 2019 establece sobre esta condición que la institución "proveerá los ambientes físicos y virtuales de aprendizaje, específicos para el desarrollo de los procesos formativos, la investigación y la extensión de acuerdo con las modalidades en que el programa se ofrezca" (MEN, 2019, p. 15).

Las preguntas que se utilizaron fueron: En una escala de 1 a 5 , donde 1 es deficiente y 5 excelente, (a) ¿Cómo evalúa usted la suficiencia, distribución y funcionalidad de la planta física y los equipos?, (b) ¿Cómo evalúa usted la calidad de los espacios físicos para el desarrollo de las actividades formativas? y (c) ¿Cómo evalúa usted la disponibilidad, actualidad y mantenimiento de los servicios informáticos? Las respuestas obtenidas en forma individual por cada pregunta se detallan en las figuras 58 a 60 .

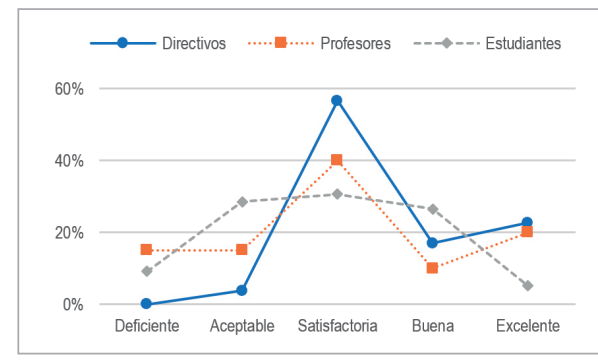

Figura 58. Suficiencia, distribución y funcionalidad de la planta física y los equipos. Fuente: elaboración propia.

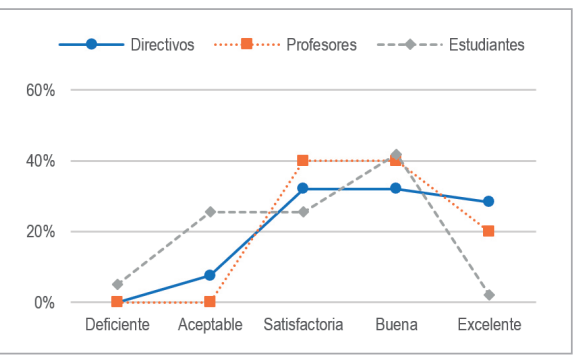

Figura 59. Calidad de los espacios físicos para el desarrollo de las actividades formativas. Fuente: elaboración propia.

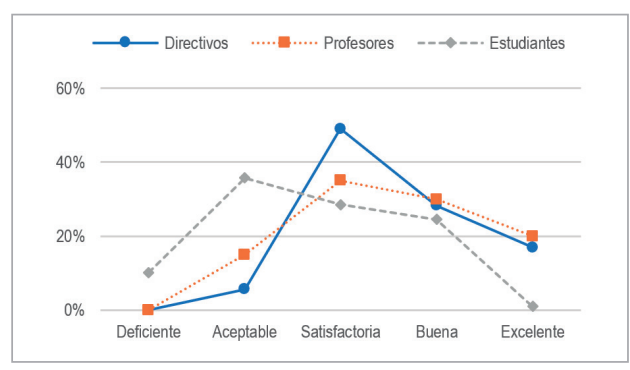

Figura 60. Disponibilidad, actualidad y mantenimiento de los servicios informáticos. Fuente: elaboración propia. 
Los datos consolidados de las preguntas sobre la infraestructura física y tecnológica, utilizando la mediana de las respuestas obtenidas, se grafican en las figuras 61 y 62. Los directivos muestran una tendencia a percibir estas condiciones principalmente en términos de bueno $(28,3 \%)$ y satisfactorio (49,1\%); los profesores centran su opinión en términos de bueno (30,0\%) y satisfactorio (40,0\%), y los estudiantes en bueno $(26,5 \%)$ y satisfactorio $(28,6 \%)$. Por otra parte, la percepción obtenida sobre la calidad de los componentes de esta condición es mucho mayor que la esperada en directivos en el rango satisfactorio y profesores en el rango bueno y satisfactorio, pero se presenta un fenómeno contrario en la percepción de los estudiantes, la cual es inferior a la esperada en todos los rangos de calificación.

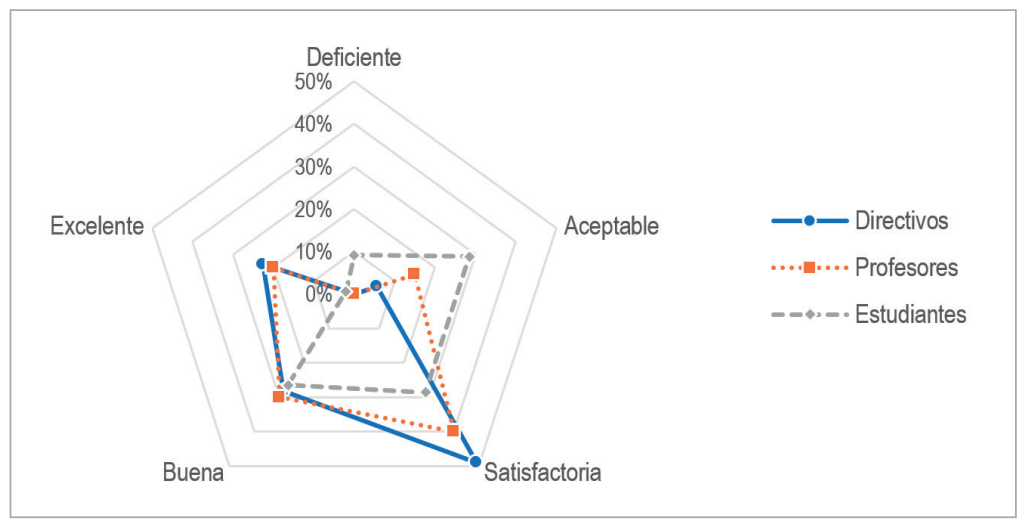

Figura 61. Percepción consolidada sobre la condición "infraestructura física y tecnológica". Fuente: elaboración propia.

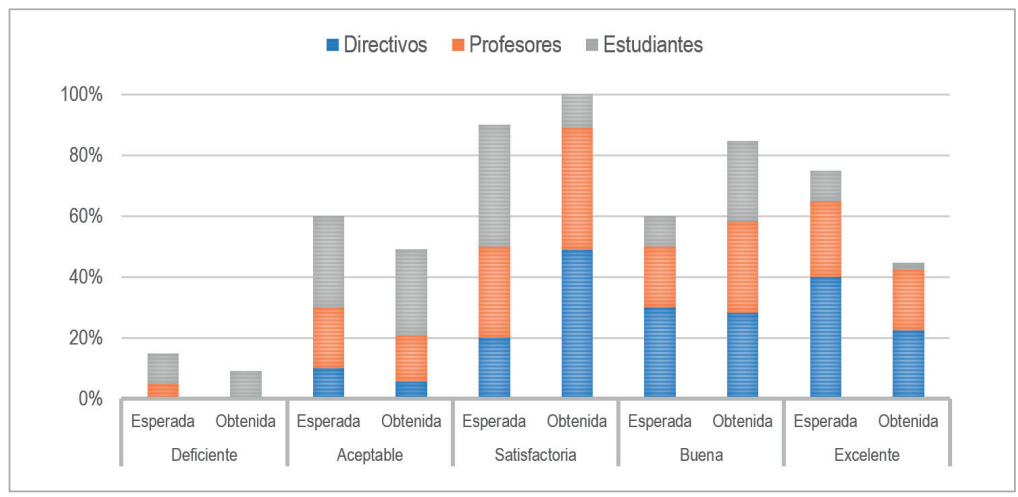

Figura 62. Comparación consolidada entre la percepción esperada y la obtenida sobre la condición "infraestructura física y tecnológica".

Fuente: elaboración propia. 


\section{Discusión final y conclusiones}

Un primer aspecto para resaltar es que los datos obtenidos, analizados en forma consolidada (figura 63), muestran que la percepción de los tres grupos observados (directivos, profesores y estudiantes) sobre la calidad de las condiciones del programa de Ingeniería Aeronáutica del Cemil-Esave se mantiene concentrada entre los rangos medio y alto de satisfacción general, esto es, excelente $(20,0 \%)$, bueno $(32,1 \%)$ y satisfactorio $(38,8 \%)$. Si bien todos los cálculos se realizaron utilizando la mediana para que los extremos en las observaciones de cualquiera de los grupos no afectaran la identificación de la tendencia central de las percepciones, los resultados obtenidos a través de una media aritmética conservan la misma consistencia.

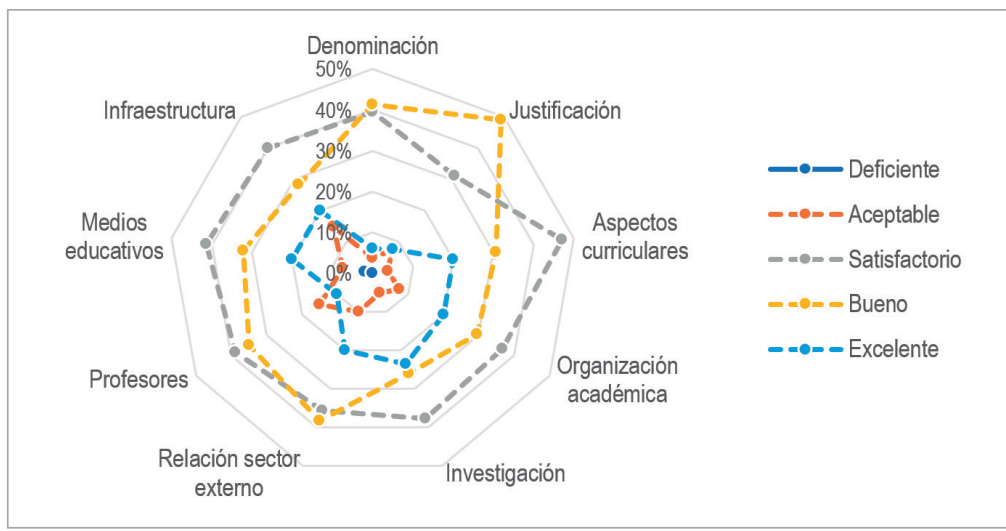

Figura 63. Percepción consolidada sobre las condiciones de calidad del programa de Ingeniería Aeronáutica de la Esave.

Fuente: elaboración propia.

Con estas cifras, se probaron en cierta forma como incorrectas las tres hipótesis formuladas con base en los grupos focales $(\mathrm{H})$, las cuales anticipaban que los tres grupos tendrían una visión diferencial respecto al grado de cercanía con la Esave. En efecto, si bien se probó correcta la H1 (el grupo de los directivos tendría una visión bastante positiva de las condiciones de calidad del programa en razón al sentido de pertenencia con la institución y el espíritu de cuerpo), las hipótesis H2 (el cuerpo de profesores tendría una visión intermedia sobre las condiciones de calidad del programa, más propensa a la crítica en razón a su experiencia con otras instituciones educativas e interrelación 
con los estudiantes) y la H3 (el cuerpo de estudiantes expresaría en una forma más enfática las oportunidades de mejora del programa y de la institución) no arrojaron los resultados esperados. En otras palabras, aunque los profesores y los estudiantes se mantuvieron críticos de algunos aspectos del programa de Ingeniería Aeronáutica, estos grupos mantienen una consideración positiva del programa y reconocen su calidad. Aunque la mediana de la percepción de los directivos (excelente: $23,1 \%$, bueno: $27,4 \%$, satisfactorio: $43,4 \%$, aceptable: $5,2 \%$, deficiente: $0,0 \%$ ) y profesores (excelente: $20,0 \%$, bueno: $40,0 \%$, satisfactorio: $36,3 \%$, aceptable: $6,3 \%$, deficiente: $0,0 \%$ ) es generalmente más alta que la mediana de la percepción de los estudiantes (excelente: 4,1\%, bueno: $31,4 \%$, satisfactorio: $36,5 \%$, aceptable: $16,8 \%$, deficiente: $3,6 \%$ ), la calidad de las condiciones del programa mantiene una buena percepción (figura 64).

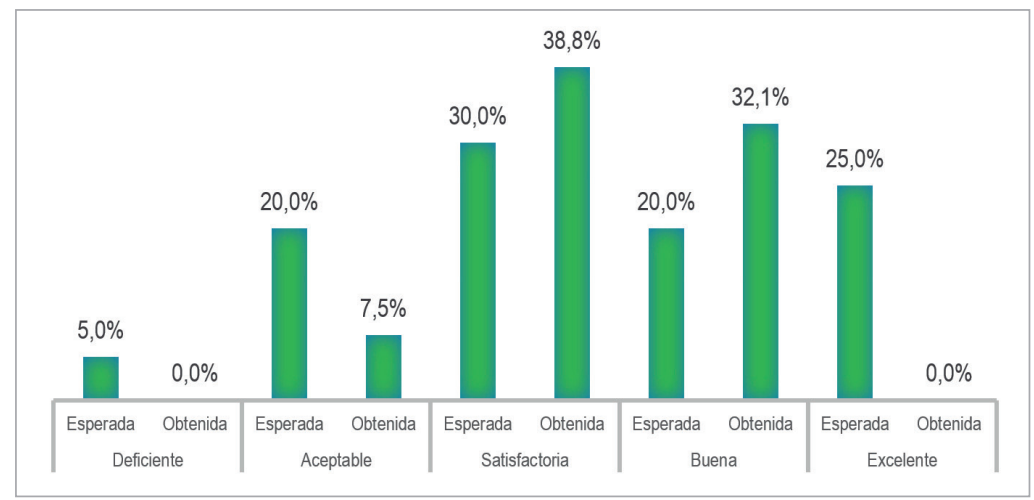

Figura 64. Comparación consolidada entre la percepción esperada y la obtenida sobre las condiciones de calidad del programa de Ingeniería Aeronáutica de la Esave.

Fuente: elaboración propia.

Dado que la participación en el cuestionario fue anónima, en comparación con la de los grupos focales, se puede desestimar la existencia de una obligación de los participantes por calificar en forma positiva a la institución por temor a represalias. Una posible explicación de las diferencias que se encontraron entre las percepciones de los grupos focales y los resultados de los cuestionarios puede estar en la composición de sus participantes. Si bien la participación en las dos herramientas fue completamente voluntaria, puede ser que los participantes de los grupos focales tuvieran una relación personal más estrecha que la esperada por los investigadores y, como tal, se sintieran 
llamados por el resto del grupo a demostrar una posición mucho más radical que la posición personal. Por otra parte, los momentos en los que se aplicaron las herramientas, aunque distanciados cerca de dos meses, también pueden influir en los resultados por el nivel de expectativa y cumplimiento de los intereses en el programa y la institución.

Un segundo aspecto para resaltar es que las fortalezas y las oportunidades de mejora fueron identificadas en forma unificada por todos los participantes y que, a pesar de su nivel de cercanía con la institución, los tres grupos no pierden su objetividad y se mantienen como críticos propositivos para el logro de la excelencia académica. Es así como en las condiciones "aspectos curriculares", "profesores" e "infraestructura" se identifican algunas oportunidades de mejora; por el contrario, condiciones como "actividades académicas y proceso formativo", "relación con el sector externo" y "los medios educativos" son las características que más resaltan en la institución. No obstante, este estudio debe entenderse como una foto fija de las percepciones de los directivos, profesores y estudiantes sobre la calidad de las nueve condiciones del programa de Ingeniería Aeronáutica del Cemil-Esave. Esto significa que puede emplearse como una línea de base para realizar estudios longitudinales, pero sería incorrecto generalizar sus resultados en forma independiente y descontextualizada, toda vez que los datos no cubren en detalle todos los aspectos posibles de una autoevaluación institucional en razón a su complejidad.

De esta forma, este capítulo contribuyó a atender el vacío de conocimiento existente sobre procesos de autoevaluación en el sistema de educación del Ejército Nacional de Colombia, al explorar las perspectivas de transformación educativa en el CemiL-EsAvE, tomando como caso de estudio el programa de Ingeniería Aeronáutica. Debido a la metodología utilizada y a los constantes cambios en el ambiente académico nacional en razón a la pandemia de Covid-19, los hallazgos de este estudio pueden y deben ser profundizados. Por lo tanto, se hace necesario realizar estudios de similar o mayor profundidad sobre las condiciones institucionales y de los programas académicos del Ejército Nacional de Colombia antes de sacar conclusiones definitivas sobre un tema de tanta importancia. Ahora es el momento de que las instituciones universitarias de la Fuerza, así como de sus investigadores, desarrollen herramientas de medición que les permitan, a través de la autocrítica, alcanzar la excelencia académica. 


\section{Referencias}

Amaya Cruz, M. Y., \& Rodríguez Ramírez, I. P. (2020). Oportunidad para la ingeniería civil en el desarrollo de la infraestructura terrestre del transporte aéreo de Colombia. Universidad Católica de Colombia.

Armstrong, R. L. (1987). The midpoint on a five-point Likert-type scale. Perceptual and motor skills, 64(2), 359-362.

Arnaiz Sánchez, P., \& Azorín Abellán, C. M. (2017). Autoevaluación docente para la mejora de los procesos educativos en escuelas que caminan hacia la inclusión. Revista Colombiana de Educación, (67), 227-245.

Becerra, L., \& Gelvan de Veinsten, S. B. (2010). Estudios preliminares de la aplicación del cuestionario de autoevaluación emocional (CAE) en población militar. Revista Española de Orientación y Psicopedagogía, 21(2), 503-524.

Camelo Villamil, K. (2010). Guia para el proceso de autoevaluación para escuelas de formación Fuerzas Militares de Colombia [Tesis Universidad Cooperativa de Colombia]. http://hdl.handle.net/20.500.12494/17327

Castellanos Sandoval, G. E. (2020). Desarrollo de un sistema integrado de aseguramiento de la calidad como propuesta para la gestión de una IES de carácter especial. Caso: Escuela Militar de Aviación, Colombia. En E. Serna (ed.), Revolución en la formación y la capacitación para el siglo XXI (pp. 499-511). Instituto Antioqueño de Investigación.

Centro de Educación Militar [CEMIL]. (2019). Reglamento Estudiantil Centro de Educación Militar. Centro de Educación Militar.

Centro de Educación Militar [CEMIL]. (2020a). Educación Superior. Programas académicos. https://www.esave.mil.co/escuela_aviacion_ejercito/educacion_superior/_4601068download $=Y$

Centro de Educación Militar [CEMIL]. (2020b). Organización institucional. Información de interés. https://cemil.edu.co/index.php/informacion-de-interes/organizacion-institucional/

Chemers, M. M., Hu, L., \& García, B. F. (2001). Academic self-efficacy and first year college student performance and adjustment. Journal of Educational Psychology, 93(1), 55-64.

Consejo Nacional de Acreditación [CNA]. (2019). Sistema de Aseguramiento de la Calidad de la Educación Superior - CNA. https://www.cna.gov.co/1779/w3-article-402539.html?_ noredirect $=1$

Comando de Educación y Doctrina [CEDOC]. (2019). Estatuto General de la Institución Universitaria Comando de Educación y Doctrina. Institución Universitaria Comando de Educación y Doctrina.

Correa Martínez, A., Valiente Sandó, P., \& Ruiz Nápoles, J. B. (2013). Evaluación de la satisfacción de los estudiantes de la filial universitaria del Hospital Militar de Holguín. LUZ, 12(2), 1-13.

Croasmun, J. T., \& Ostrom, L. (2011). Using Likert-Type Scales in the Social Sciences. Journal of Adult Education, 40(1), 19-22.

Díaz Bocanegra, C. A. (2018). La confiabilidad como herramienta para mejorar el alistamiento de las aeronaves de la Aviación del Ejército. Universidad Militar Nueva Granada. 
Escuela de Aviación del Ejército [ESAVE]. (2017). Proyecto Educativo del Programa. Centro de Educación Militar.

Escuela de Aviación del Ejército [ESAVE]. (2019). Historia. https://www.esave.mil.co/index. php? idcategoria $=189843$ \&print $\&$ inf $=0$

Escuela de Aviación del Ejército [ESAVE]. (2020). Autoevaluación institucional. https://www. esave mil.co/?idcategoria $=4606968$ download $=Y$

Escuela de Ingenieros Militares [ESING]. (2020). Cultura de autoevaluación. https://www. esing.mil.co/escuela_ingenieros_militares/educacion_superior/autoevaluacion/cultura_ autoevaluacion\&download $=\mathrm{Y}$

Escuela de Inteligencia y Contrainteligencia del Ejército [ESICI]. (2020). Procedimientos de autoevaluación. http://esici.cemil.edu.co/index.php/procedimientos-basicos-de-autoevaluacion/

Espinoza, O., \& Poblete, A. (1994). Manual de autoevaluación para las instituciones de educación superior 199 (Número January).

Flórez-Nisperuza, E. P., \& Hoyos-Merlano, A. M. (2020). Una mirada cualitativa sobre la autoevaluación institucional desde la praxis universitaria. Revista Científica, 37(1), 78-89. https://doi.org/10.14483/23448350.13645

Fraile Aranda, A. (2020). La autoevaluación: una estrategia docente para el cambio de valores educativos en el aula. Ser Corporal, (3), 6-18.

García, A., Velasco Forero, M., \& Peñaloza de Arias, M. (2013). Autoevaluación institucional en Colombia y Venezuela. Referencias actuales. Revista Evaluación e Investigación, 7(1), 11-30.

González González, J., Galindo Miranda, N. E., Galindo Miranda, J. L., \& Morgan, M. G. (2004). Los paradigmas de la calidad educativa: de la autoevaluación a la acreditación. IESALC.

Guacaneme González, J. V., \& Segura Folleco, I. J. (2013). Análisis de preinversión para el proyecto de un simulador de vuelo para el helicóptero MI 17 del Ejército de Colombia [Título de especialización, Universidad Militar Nueva Granada]. Repositorio UNIMILITAR. https://repository.unimilitar.edu.co/bitstream/handle/10654/9286/ GuacanemeGonzalezJoseVicente2013.pdf? sequence=2\&isAllowed $=y$

Guillén Vivas, X., Almuiñas Rivero, J., Galarza López, J., Alarcón Ramírez, L., Loor Avila, K., \& Gallegos Macías, M. (2018). Autoevaluación institucional con fines de acreditación en las Instituciones de Educación Superior de América Latina. Educación Médica Superior, 32(1), 1-18.

Hamui-Sutton, A., \& Varela-Ruiz, M. (2013). La técnica de grupos focales. Investigación en Educación Médica, 2(1), 55-60.

Henao Monsalve, J. (2018). Aproximación prospectiva para determinar las competencias del ingeniero aeronáutico de la Universidad Pontificia Bolivariana para el 2005 [Tesis de pregrado, Universidad Pontificia Bolivariana]. Repositorio UPB. https://repository.upb.edu.co/bitstream/handle/20.500.11912/4190/Aproximaci\%c3\%b3n\%20 prospectiva $\% 20$ para $\% 20$ determinar $\% 20$ las $\% 20$ competencias $\% 20$ del $\% 20$ ingeniero $\% 20$ aeron $\%$ c3\%alutico\%20de\%20la.pdf?sequence=1 \&isAllowed=y 
Holmes, D. S. (1971). Conscious self-appraisal of achievement motivation: The self-peer rank method revisited. Journal of Consulting and Clinical Psychology, 36(1), 23-26.

Hoyos Arango, A. (2010). Modelo para aplicación de RCM aeronáutico en Colombia. Universidad EAFIT.

Jaramillo, O., \& Villegas, L. E. (1998). La biblioteca universitaria: Autoevaluación y acreditación. Revista Interamericana de Bibliotecología, 21(2), 49-60.

Jefatura de Estado Mayor de Planeación y Políticas. (2019). Lineamientos del Sistema Articulado de Aseguramiento de la Calidad Educativa del Ejército Nacional. Ejército Nacional de Colombia.

Joshi, A., Kale, S., Chandel, S., \& Pal, D. K. (2015). Likert Scale: Explored and Explained. Current Journal of Applied Science and Technology, 7(4), 396-403.

Juncos, A. E., \& Pomorska, K. (2014). Manufacturing Esprit de Corps: The Case of the European External Action Service. Journal of Common Market Studies, 52(2), 302-319. https:// doi.org/10.1111/jcms.12107

Londońo Salazar, J. E., \& Ramírez González, D. A. (2012). Cultura de la autoevaluación: cimiento para la acreditación de programas académicos en modalidad virtual. Revista Virtual Universidad Católica del Norte, (36), 1-6.

López-de-Arana Prado, E., Aramburuzabala Higuera, P., \& Opazo Carvajal, H. (2019). Diseño y validación de un cuestionario para la autoevaluación de experiencias de aprendizaje-servicio universitario. Educación XX1, 23(1), 319-347. https://doi.org/10.5944/ educXX1.23834

López Pastor, V. (2004). La participación del alumnado en los procesos evaluativos: la autoevaluación y la evaluación compartida en educación física. En A. Fraile Aranda (ed.), Didáctica de la Educación Física: una perspectiva critica y transversal (pp. 265-291). Biblioteca Nueva.

Losio, M. S., \& Macri, A. (2015). Deserción y rezago en la universidad. Indicadores para la autoevaluación. Revista Latinoamericana de Políticas y Administración de la Educación, 2(3), 114-126.

Manning, F. J. (1991). Morale, cohesion, and esprit de corps. En R. Gal \& D. Mangelsdorff (eds.), Handbook of military psychology (pp. 453-470). John Wiley \& Sons.

Ministerio de Defensa Nacional. (2019). Política Educativa de la Fuerza Pública (PEFuP) 2019-2032: Hacia una educación inteligente, estratégica y de calidad. Ministerio de Defensa Nacional.

Ministerio de Educación Nacional [MEN]. (2008). Guía para el mejoramiento institucional. Ministerio de Educación Nacional.

Ministerio de Educación Nacional [MEN]. (2013). Guía de autoevaluación para el mejoramiento institucional. Ministerio de Educación Nacional.

Ministerio de Educación Nacional [MEN]. (2015). Decreto 1075. Ministerio de Educación Nacional.

Ministerio de Educación Nacional [MEN]. (2019). Decreto 1330. Ministerio de Educación Nacional. 
Ministerio de Educación Nacional [MEN]. (2020a). Acuerdo 02. Por el cual se actualiza el modelo de acreditación en alta calidad. Ministerio de Educación Nacional.

Ministerio de Educación Nacional [MEN]. (2020b). Resolución N. o 021795. Por la cual se establecen los parámetros de autoevaluación, verificación y evaluación de las condiciones de calidad de programa reglamentadas en el Decreto 1075 de 2015, modificado por el Decreto 1330 de 2019, para la obtención, modificación y renovación del registro calificado. Ministerio de Educación Nacional.

Motivar García, E. (2015). Evaluación del aprendizaje de los estudiantes de la Escuela de Aviación del Ejército. [Tesis de especialización, Universidad Militar Nueva Granada]. Repositorio UNIMILITAR. https://repository.unimilitar.edu.co/bitstream/ handle/10654/6261/EVALUACION\%20DEL\%20APRENDIZAJE\%20DE\%20 LOS\%20ESTUDIANTES\%20ESAVE.pdf?sequence=2\&isAllowed=y

Murcia-Peña, N., Murcia-Gómez, N., \& Murcia-Gómez, J. (2009). Imaginarios sociales y autoevaluación universitaria. Educación y Educadores, 12(3), 99-115.

Murillo Estepa, P. (2008). La autoevaluación institucional: un camino importante para la mejora de los centros educativos. Revista del Forum Europeo de Administradores de la Educación, (1), 13-17.

Newcomb, T. M. (1943). Personality and social change; attitude formation in a student community. Dryden Press. https://psycnet.apa.org/record/1943-03460-000

Organización para la Cooperación y el Desarrollo Económicos [OCDE]. (2016). La educación en Colombia. OCDE.

Pabón Fernández, N. (1996). Autoevaluación institucional en la perspectiva de la autorregulación: fundamento para la autonomía universitaria. Pedagogía y Saberes, (8), 37-54.

Palacios García, W. D. (2013). La calidad de la educación superior en perspectiva comparada: Propuesta de un modelo de autoevaluación dentro del sistema de garantía interna de calidad de las universidades. Universidad Autónoma de Madrid.

Panadero-Calderón, E., \& Alonso-Tapia, J. (2013). Revisión sobre autoevaluación educativa: evidencia empírica de su implementación a través de la autocalificación sin criterios de evaluación, rúbricas y guiones. Revista de Investigación en Educación, 11(2), 172-197.

Paulsen Fernández, J. C. (2018). Módulo de autoevaluación EPHE y su influencia en la mejora del clima institucional del Colegio Militar Leoncio Prado, Callao, 2016 [Tesis de maestría, Universidad San Pedro]. Repositorio Institucional. http://publicaciones. usanpedro.edu.pe/handle/USANPEDRO/5103

Pinto Guzmán, L. L. (2017). Análisis del sistema de educación militar para oficiales y suboficiales del Ejército Nacional, desde la Escuela de Armas y Servicios, a la transformación del Ejército en el contexto del posconflicto [Tesis de maestría, Universidad Externado de Colombia]. Repositorio Institucional. https://bdigital.uexternado.edu.co/bitstream/ handle/001/899/ARA-Spa-2017-\%20An\%C3\%A1lisis\%20_del_sistema_de_educaci\%C3\%B3n_militar_para_oficiales_y_suboficiales_Trabajo_de_Grado.pdf?sequence=1\&isAllowed $=y$

Pontificia Universidad Javeriana. (2020). Nueva oferta académica de la Javeriana. Entrevista con Luis David Prieto, vicerrector académico. Pontificia Universidad Javeriana. 
Prieto Rodríguez, M. A., \& March Cerdáb, J. C. (2002). Paso a paso en el diseño de un estudio mediante grupos focales. Atención Primaria, 29(6), 366-373.

Putwain, D. W., Symes, W., \& Remedios, R. (2016). The impact of fear appeals on subjective-task value and academic self-efficacy: The role of appraisal. Learning and Individual Differences, (51), 307-313.

Ramírez, M. T., \& Salazar, I. (2010). El surgimiento de la educación en Colombia: ¿En qué fallamos? En Economía colombiana del siglo XIX (pp. 1-72). Universidad Nacional Autónoma de México.

Ramírez Rubiano, E., \& Ramírez Bravo, R. (2015). Educación en el Ejército Nacional de Colombia y el posconflicto. Revista Criterios, 22(1), 199-214.

Reed, M. (2017). Understanding and responding to negativism in schooling: the potential of the 'double move'. Learning, Culture and Social Interaction, (12), 63-77. https://doi. org/10.1016/j.lcsi.2016.10.001

Salazar, R. D. (2013). Prospectiva de la Ingeniería Aeronáutica en Colombia. Ingenium Revista de la Facultad de Ingeniería, 14(27), 2-5. https://doi.org/10.21500/01247492.2584

Sánchez Martínez, N. R. (2018). Formación para el desarrollo del talento humano en el sector aeronáutico y aeroespacial en Colombia. [Tesis de especialización, Universidad Militar Nueva Granada]. Repositorio UNIMILITAR. https://repository.unimilitar.edu.co/bitstream/ handle/10654/17906/SanchezMartinezNubiaRocio2018.pdf?sequence=3\&isAllowed=y

Singhapakdi, A., \& Vitell, S. J. (2007). Institutionalization of ethics and its consequences: a survey of marketing professionals. Journal of the Academy of Marketing Science, 35(2), 284-294. https://doi.org/10.1007/s11747-007-0030-8

Sistema Nacional de Información de la Educación Superior [SNIES]. (2021). Información del programa. Consultas públicas. https://hecaa.mineducacion.gov.co/consultaspublicas/ detallePrograma

Stecconi, C. (2014). Inteligencias múltiples y el cuestionario de autoevaluación. Calidad de Vida, 1(5), 147-164.

Trippi, J., \& Stewart, J. B. (1989). The relationship between self-appraisal variables and the college grade performance and persistence of Black freshmen. Journal of College Student Development, 30(6), 484-491.

Valdés Rojas, M. B., Alfonso Nazco, M., Remedios González, J. M., \& Echemendía Arce, D. M. (2015). El proceso de autoevaluación en las instituciones universitarias pedagógicas: Una estrategia para su mejora. Gaceta Médica Espirituana, 17(2), 39-49.

Van Kraayenoord, C. E., \& Paris, S. G. (1997). Australian students's self-appraisal of their work samples and academic progress. The Elementary School Journal, 97(5), 523-537.

Vidales Moreno, A., Vargas Hernández, L. A., \& Sarmiento, J. E. (2011). Sistema Educativo para la Fuerza Aérea Colombiana: "Universidad del Aire y del Espacio" [Tesis de maestría Universidad de la Sabana]. Repositorio Institucional. https://intellectum.unisabana.edu.co/handle/10818/1371

Vitell, S. J., \& Singhapakdi, A. (2008). The role of ethics institutionalization in influencing organizational commitment, job satisfaction, and esprit de corps. Journal of Business Ethics, 81(2), 343-353. https://doi.org/10.1007/s10551-007-9498-x 